\title{
Direct Liquid Fuel Cells - The Influence of Temperature and Dynamic
}

\section{Instabilities}

\author{
Jéssica A. Nogueira and Hamilton Varela* \\ Instituto de Quimica de Sao Carlos, Universidade de Sao Paulo, P.O. Box 780, 13560-970, \\ São Carlos, SP, Brazil
}

\begin{abstract}
The interconversion between chemical and electrical energies plays a pivotal role in the challenge for a sustainable future. Proton exchange membrane (PEMFC) based on the electrooxidation of hydrogen and reduction of oxygen comprise a relatively mature technology of indisputable relevance. Alternatively, some open questions concerning the use of Direct Liquid Fuel Cells (DLFC) call for further experimental investigations on these systems. In this paper we evaluate the temperature effect on DLFCs under conventional and oscillatory conditions. We studied four molecules: methanol, formic acid, ethanol, and dimethyl ether. The use of identical experimental conditions allowed at studying the role of the fuel on the DLFC performance, providing thus reference values for future investigations. Under regular, non-oscillatory regime, we observed for all cases that the overpotential decreases as the temperature increases mainly because water activation on the catalyst surface is facilitated at high temperatures. By mapping the conditions where oscillatory kinetics manifest itself under galvanostatic mode, only the electro-oxidation of dimethyl ether did not exhibit potential oscillations. The relationship between oscillatory frequency and temperature during the methanol and formic acid electrooxidation followed a conventional Arrhenius dependence, whereas with ethanol there was no straightforward trend, and temperature compensation prevails. The atypical behavior found for ethanol was addressed in terms of its main electrocatalytic poisons: adsorbed $\mathrm{CO}$ and acetate. The absence of oscillations during dimethyl ether electro-oxidation was attributed to its weak interaction with the catalyst surface.
\end{abstract}

*Corresponding author: hamiltonvarela@usp.br 


\section{INTRODUCTION}

To maximize the efficiency of electrochemical devices, the oxidation and reduction reactions, which lead to the conversion of chemical to electrical energy, must occur at a high rate and the lowest overpotential. Proton exchange membrane fuel cells (PEMFC) based on the electro-oxidation of hydrogen and reduction of oxygen operate at relatively mild temperatures, 70-90 ${ }^{\circ} \mathrm{C}$, and are, currently, the fuel cell option most mature for use in electric cars, with efficiencies between 40-65\% depending on the operating conditions. ${ }^{1,2}$ Nevertheless, while the $\mathrm{H}_{2}$ electro-oxidation on Pt electrodes occurs at a high rate and presents low overpotentials, the $\mathrm{O}_{2}$ reduction to $\mathrm{H}_{2} \mathrm{O}$ is the main responsible for the activation loss, due to its slow kinetics.,

However, the electrocatalytic reduction of oxygen is not the only obstacle, the technologies surrounding a hydrogen economy still present many challenges. Although the $\mathrm{H}$ atom is an abundant element (linked to oxygen forming water or carbon forming hydrocarbons), finding $\mathrm{H}_{2}$ molecules naturally on earth is rare. ${ }^{5}$ Currently, about $96 \%$ of $\mathrm{H}_{2}$ is produced through the catalytic reform of fossil fuels (which is far from being an ecologically correct process, keeps us tied to the oil economy and produces low-purity $\mathrm{H}_{2}$ ) and $4 \%$ comes from water electrolysis (which is still economically unviable, given the energy cost due to high overpotentials for the oxygen evolution reaction). ${ }^{6}$ Besides, there are several challenges related to $\mathrm{H}_{2}$ storage and its distribution logistics. ${ }^{5}$

Accordingly, the use of the so-called Direct Liquid Fuel Cells (DLFC) ${ }^{7-10}$ with molecules such as methanol, formic acid, ethanol, or even (dissolved) gas at ambient temperature as dimethyl ether (DME), are interesting alternatives to the use of $\mathrm{H}_{2}$. However, although carbon-containing molecules have a higher chemical energy density and a standard potential close to that presented by $\mathrm{H}_{2}$ (Table 1) there is a huge kinetic limitation for the complete (and even partial) electro-oxidation of these fuels. ${ }^{9}$ The main strategy to overcome this challenge is to understand the mechanism, the rate-determining step of these reactions, and, thus, propose electrocatalysts optimized for each molecule. ${ }^{11}$ Additionally, a way to increase the rate of all reaction steps is increasing temperature. These two points can be discussed using the Arrhenius equation:

$$
k(T)=A e^{\left(-E_{a p p} / R T\right)}
$$

$k$ being the rate constant, $A$ is the pre-exponential factor, $E_{\text {app }}$ is the apparent activation energy, $R$ is the molar gas constant and $T$ is temperature. Therefore, by equation 1, decreasing the activation energy using a better electrocatalyst, or increasing the temperature, $T$, the rate constant, $k(T)$, increases. 
Table 1. Overall fuel cell reactions and their respective theoretical energy density and standard potential. $^{7,8}$

\begin{tabular}{|c|c|c|}
\hline Overall fuel cell reaction & $\begin{array}{c}\text { energy density } \\
\left(\mathbf{W h ~ L}^{-1}\right)\end{array}$ & $\begin{array}{c}\text { standard potential } \\
(\mathbf{V})\end{array}$ \\
\hline $\begin{array}{c}\mathrm{H}_{2}+(1 / 2) \mathrm{O}_{2} \rightarrow \mathrm{H}_{2} \mathrm{O} \\
\left(70 \text { bar a } 25^{\circ} \mathrm{C}\right)\end{array}$ & 1800 & 1.23 \\
\hline $\mathrm{HCOOH}+(1 / 2) \mathrm{O}_{2} \rightarrow \mathrm{CO}_{2}+\mathrm{H}_{2} \mathrm{O}$ & 2103 & 1.40 \\
\hline $\mathrm{CH}_{3} \mathrm{OH}+(3 / 2) \mathrm{O}_{2} \rightarrow \mathrm{CO}_{2}+2 \mathrm{H}_{2} \mathrm{O}$ & 5897 & 1.21 \\
\hline $\mathrm{CH}_{3} \mathrm{CH}_{2} \mathrm{OH}+3 \mathrm{O}_{2} \rightarrow 2 \mathrm{CO}_{2}+3 \mathrm{H}_{2} \mathrm{O}$ & 6307 & 1.15 \\
\hline $\mathrm{CH}_{3} \mathrm{OCH}_{3}+3 \mathrm{O}_{2} \rightarrow 2 \mathrm{CO}_{2}+3 \mathrm{H}_{2} \mathrm{O}$ & 5610 & 1.19 \\
\hline
\end{tabular}

A third, yet unconventional, way to increase a reaction efficiency would be through autonomous $^{12-19}$ and/or externally driven oscillations. ${ }^{20-24}$ As described by Ross and coworkers, ${ }^{25,26}$ one can increase efficiency and minimize dissipative processes by periodically changing some of the parameters of non-linear reactions, which include, for example, heterogeneous and electrochemical catalysis. The mathematical contours of the claim that oscillations can lead to lower dissipation were already addressed for electrochemical systems. ${ }^{12,17}$ In short, the available energy to do work in a fuel cell, $P_{\text {out }}$, can be given as:

$$
P_{\text {out }}=E_{\text {cell }} j
$$

where $\mathrm{E}_{\mathrm{cell}}$ is the potential difference or voltage of an electrochemical device and $j$ is the current density. In turn, the efficiency, $\varepsilon$, can be defined as:

$$
\varepsilon=P_{\text {out }} / P_{\text {in }}
$$

In contrast, $P_{\text {in }}$ is the total chemical energy that can be converted to electrical power. Finally, dissipation is the energy wasted during this conversion:

$$
D=P_{\text {in }}-P_{\text {out }}
$$

In steady-state, the voltage and current are constant. Therefore, the dissipation, in this case, is also constant and greater than zero for any irreversible process. To result in higher efficiency, a periodic change must lead to a lower dissipation on average, $\left\langle D_{o s c}\right\rangle$, compared to the value in a stationary condition, $D$ :

$$
\Delta D=<D_{\text {osc }}>-D
$$

Under oscillatory conditions, $E_{\text {cell }}$ or even $j$ vary over time, and the phase between these two properties, as well as their average values, determines efficiency and dissipation, allowing $\Delta D$ to assume negative values.

Alongside there is the idea of a self-cleaning process: periodically and without external stimulus the electrode surface is oxidized, preventing its deactivation due to strongly adsorbed 
intermediates (such as adsorbed $\mathrm{CO}, \mathrm{CO}_{\mathrm{ad}}$ ) that accumulate on the electrocatalyst surface, decreasing its number of available active sites. ${ }^{13}$ As far as practical systems are concerned, it is known that proton exchange membrane fuel cells (PEMFC) fed with $\mathrm{H}_{2}$ contaminated with $\mathrm{CO}^{14-17}$ or formic acid ${ }^{18,19}$ operated in autonomous oscillatory conditions present an average performance superior to that observed in the quasi-stationary state. Additionally, this increase in efficiency is also observed when the concentration of the reagents is changed periodically by an external controller, ${ }^{20}$ or even by programmed pulses of current and/or potential. ${ }^{21-24}$

In this article, we provide a short outlook about DLFC fed with carbon-containing fuels - direct methanol fuel cell (DMFC), direct formic acid fuel cell (DFAFC), direct ethanol fuel cell (DEFC), and direct dimethyl ether fuel cell (DDMEFC) - and then evaluate the effect of temperature on such devices- under regular and oscillatory conditions. We focus primarily on the self-organized manifestation of oscillatory kinetics during the electro-oxidation of methanol, formic acid, ethanol, and dimethyl ether (DME). Except for the latter, there are several studies on potential and/or current oscillations during the electro-oxidation of small organic molecules in half-cell experiments, ${ }^{12,13,27-39}$ but studies in practical systems are still scarce. Also, of the few that exist, ${ }^{17,19,40-42}$ none is dedicated to exploring the effect of temperature on cell dynamics, although this is a fundamental bifurcation parameter in the oscillations observed in the PEMFC anode. ${ }^{43}$ 


\section{EXPERIMENTAL SECTION}

The methodology used here is based on the work of Paganin et al. ${ }^{44}$ and is also detailed in a recent paper of our Group. ${ }^{19}$ Briefly, as anodic and cathodic electrocatalysts were used Pt/C (50 wt $\%$ ) from Alfa Aesar and the metal charge was $1 \mathrm{mg}_{\mathrm{Pt}} \mathrm{cm}^{-2}$ at both electrodes. The polymeric electrolyte was a preconditioned Nafion ${ }^{\circledR} 115$ membrane $(125 \mu \mathrm{m})^{44}$ and the geometric area of the electrodes was $\approx 4.6 \mathrm{~cm}^{2}$ (current densities were calculated based on this geometric area).

The single-cell tests were conducted at five temperatures: $30,40,50,60$, and $70{ }^{\circ} \mathrm{C}$. The fuel flow to the anode was kept at $2 \mathrm{~mL} \mathrm{~min}^{-1}$ using a Watson Marlow 520Di peristaltic pump. The aqueous solutions of methanol (J. T. BAKER, 99.8\%) for DMFC and ethanol (SigmaAldrich, 95\%) for DEFC were $2 \mathrm{~mol} \mathrm{~L}^{-1}$. For the DDMEFC, we used a DME saturated solution, $\approx 1.6 \mathrm{~mol} \mathrm{~L}{ }^{-1} .{ }^{45}$ Finally, the concentration of formic acid (Panreac, 98\%) used for DFAFC was $8 \mathrm{~mol} \mathrm{~L}^{-1}$ (in some cases we used a lower concentration, as indicated in the figure caption).

To avoid the polarity inversion of the cell voltage and evaluate only the anodic processes, ${ }^{19} \mathrm{H}_{2}$ was used at the cathode. In this arrangement, the cathode acts as a dynamic hydrogen electrode $(\mathrm{DHE})^{46}$ and the cell voltage expressed versus this reference. The electrochemical experiments were carried out with an Autolab/Eco Chemie PGSTAT320N potentiostat. The impedance spectra were obtained in potentiostatic mode, ranging from 100,000 to $0.01 \mathrm{~Hz}$ and the amplitude of the sinusoidal signal was $10 \mathrm{mV}$. The real $\left(Z^{\prime}\right)$ and imaginary $\left(Z^{\prime \prime}\right)$ parts of the impedance at the Nyquist plots were multiplied by the geometric area of the electrodes, $4.6 \mathrm{~cm}^{2}$. 


\section{RESULTS AND DISCUSSION}

\subsection{Direct Methanol Fuel Cell}

The first step to evaluate the impact of the temperature during the electro-oxidation of methanol in a DMFC was by slow linear sweep voltammetry $\left(1 \mathrm{mV} \mathrm{s}^{-1}\right)$ at different temperatures, from 30 to $70{ }^{\circ} \mathrm{C}$, as shown in Figure 1 .

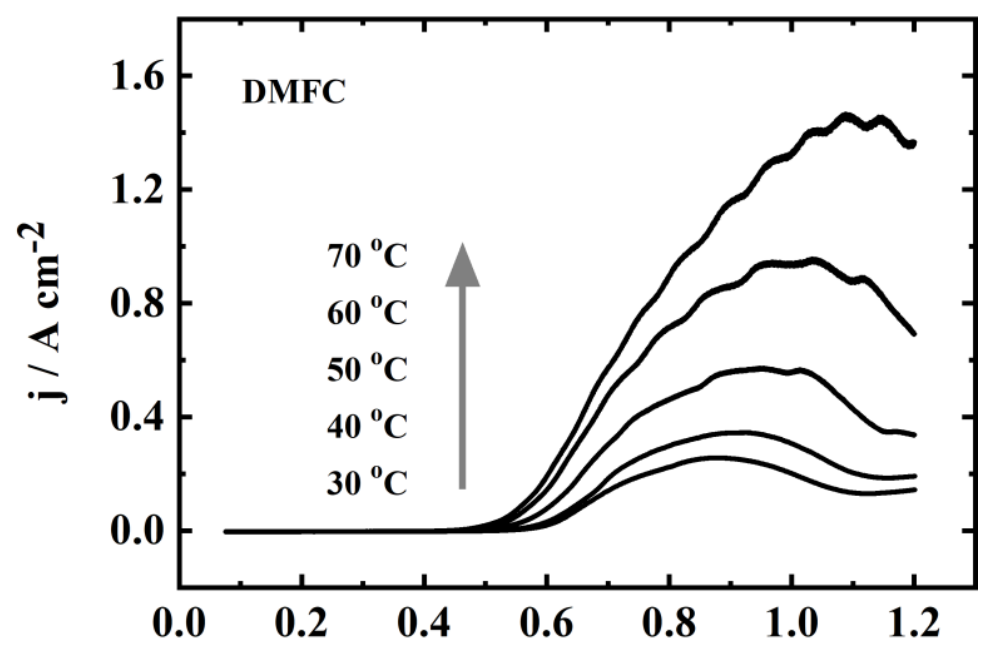

E vs. DHE / V

Figure 1. Linear potential sweeps for the DMFC at different temperatures, ranging from 30 to $70^{\circ} \mathrm{C}$; the gray arrow indicates the direction of the temperature increase. Experimental conditions: anodic and cathodic electrocatalyst $=\mathrm{Pt} / \mathrm{C}\left(1 \mathrm{mg}_{\mathrm{Pt}} \mathrm{cm}^{-2}\right) ;\left[\mathrm{CH}_{3} \mathrm{OH}\right]=2 \mathrm{~mol} \mathrm{~L}$ ${ }^{1}$; fuel flow to the anode $=2 \mathrm{~mL} \mathrm{~min}^{-1} ; \mathrm{H}_{2}$ at the cathode - dynamic hydrogen electrode (DHE), $\mathrm{dE} / \mathrm{dt}=1 \mathrm{mV} \mathrm{s}^{-1}$.

The most straightforward feature presented in Figure 1 is the current enhancement accompanying the temperature increase. The use of $\mathrm{H}_{2}$ at the cathode restricts the investigation to the anodic processes, however, the oxygen reduction reaction is also thermally activated ${ }^{47}$ and, one should expect an increase in the cell voltage $\left(E_{c e l l}=E_{c a t}-E_{a n}\right)$ at higher temperatures. It is worth noting that this gain in terms of lower overpotentials usually outweighs the negative effect of the methanol crossover, which is favored as the temperature increases. ${ }^{48,49}$ The current density at $0.90 \mathrm{~V}$ jumps from $0.25 \mathrm{~A} \mathrm{~cm}^{-2}$ to $1.16 \mathrm{~A} \mathrm{~cm}^{-2}$, and the onset potential is shifted to lower values, a $0.10 \mathrm{~V}$ decrease in the overpotential, by increasing the temperature from 30 to $70{ }^{\circ} \mathrm{C}$.

These facts reinforce the fundamental role that temperature plays in (electro)catalysis. If by increasing the temperature, the current density reached in the same potential value is increased (in other words, greater electrical power, $P_{\text {out, }}$ that can be used to do work, 
equation 2), we have an attractive approach in kinetically limited processes. However, even at $70{ }^{\circ} \mathrm{C}$, part of the chemical energy contained in the methanol molecules $\left(P_{\text {in }}\right)$ is lost during its electro-oxidation by activation, since the reaction only starts at $0.44 \mathrm{~V}$ (in comparison with the standard potential, $\left.E_{\mathrm{CH}_{3} \mathrm{OH}}^{o}=0.016 \mathrm{~V}\right){ }^{6}$ The complete conversion of methanol to $\mathrm{CO}_{2}$ involves the transfer of six electrons through several steps that can be summarized in two parallel paths: i) the indirect pathway where $\mathrm{CH}_{3} \mathrm{OH}$ undergoes consecutive dehydrogenations ( $\mathrm{r} 1$ and $\mathrm{r} 2$ ) until $\mathrm{CO}_{\mathrm{ad}}$, and ii) the direct one that leads to the incomplete oxidation products - formaldehyde ( $\mathrm{r} 3$ and $\mathrm{r} 4$ ) and formic acid ( $\mathrm{r} 6$ and $\mathrm{r} 8$ ) - and $\mathrm{CO}_{2}$ through an active intermediate ( $\mathrm{r} 6$ and r7). ${ }^{50-52}$ This active intermediate is normally attributed to the adsorbed formate (r6), ${ }^{53}$ as shown in the reactions below:

$$
\begin{gathered}
\mathrm{CH}_{3} \mathrm{OH}+3 \mathrm{Pt} \rightarrow \mathrm{HCO}_{\mathrm{ad}}+2 \mathrm{Pt}+3 \mathrm{H}^{+}+3 \mathrm{e}^{-} \\
\mathrm{HCO}_{\mathrm{ad}} \rightarrow \mathrm{CO}_{\mathrm{ad}}+\mathrm{H}^{+}+\mathrm{e}^{-} \\
\mathrm{CH}_{3} \mathrm{OH}+\mathrm{Pt} \rightarrow \mathrm{H}_{3} \mathrm{CO}_{\mathrm{ad}}+\mathrm{H}^{+}+\mathrm{e}^{-} \\
\mathrm{H}_{3} \mathrm{CO}_{\mathrm{ad}} \rightarrow \mathbf{H C H O}+\mathrm{Pt}+\mathrm{H}^{+}+\mathrm{e}^{-} \\
\mathrm{Pt}+\mathrm{H}_{2} \mathrm{O} \rightarrow \mathrm{OH}_{\mathrm{ad}}+\mathrm{H}^{+}+\mathrm{e}^{-} \\
\mathrm{HCO}_{\mathrm{ad}}+\mathrm{OH}_{\mathrm{ad}} \rightarrow \mathrm{HCOO}_{\mathrm{ad}}+\mathrm{Pt}+\mathrm{H}^{+}+\mathrm{e}^{-} \\
\mathrm{HCOO}_{\mathrm{ad}} \rightarrow \mathbf{C O}_{2}+2 \mathrm{Pt}+\mathrm{H}^{+}+\mathrm{e}^{-} \\
\mathrm{HCOO}_{\mathrm{ad}}+\mathrm{H}^{+}+\mathrm{e}^{-} \rightarrow \mathbf{H C O O H}+2 \mathrm{Pt} \\
\mathrm{CO}_{\mathrm{ad}}+\mathrm{OH}_{\mathrm{ad}} \rightarrow \mathbf{C O}_{2}+2 \mathrm{Pt}+\mathrm{H}^{+}+\mathrm{e}
\end{gathered}
$$

Both formaldehyde and formic acid can diffuse and return to the solution or remain near the catalyst and be further oxidized to $\mathrm{CO}_{2}$ (if they are trapped inside the diffusion layer or in the case of a recirculating system).

As we can anticipate from the reactions above, at low potentials, when the Pt surface is reduced, $\mathrm{CH}_{3} \mathrm{OH}$ is continuously dehydrogenated, forming $\mathrm{H}_{\mathrm{x}} \mathrm{CO}_{\mathrm{ad}}$ and $\mathrm{CO}_{\mathrm{ad}}(\mathrm{r} 1$ and $\mathrm{r} 2)$. These adsorbates occupy active sites on Pt surface, preventing the reaction progress. That is, although a higher temperature leads to a higher rate of methanol dehydrogenation (intrinsic rate), the electrode available area gradually decreases and, therefore, the current is low at $E<0.40 \mathrm{~V}{ }^{52}$ This explains why at low potentials the system is less sensitive to temperature. The scenario changes at higher potentials because Pt oxidation ( $\mathrm{r} 5$ ) is also controlled by activation. ${ }^{54} \mathrm{An}$ increase in temperature leads to an increase in the extent of surface oxidation (the $\mathrm{OH}$ adsorption, $r 5$, is facilitated), which, in turn, results in a decrease of the onset potential for the methanol electro-oxidation. ${ }^{52}$ To oxidize the carbonaceous adsorbed intermediates, the formation of $\mathrm{PtOH}$ is necessary ( $\mathrm{r} 6$ and $\mathrm{r}$ 9). The $\mathrm{HCO}_{\mathrm{ad}}$ intermediate (r1) reacts with $\mathrm{PtOH}(\mathrm{r} 5)$ forming adsorbed formate (r6), which can be converted to $\mathrm{HCOOH} \mathrm{(r8)} \mathrm{or} \mathrm{CO}_{2}$ (r7). In addition, 
$\mathrm{CO}_{\mathrm{ad}}$ also reacts with $\mathrm{OH}_{\mathrm{ad}}$ to form $\mathrm{CO}_{2}$ (r9). Only with the removal of these species, free active sites are available for the adsorption of methanol, its dehydrogenation, and oxidation of its fragments, which leads to an increase in the current density observed in Figure 1 above the onset potential, that is, above the potential where the formation of oxygenated Pt species starts. ${ }^{50,52}$ As the potential increases, eventually, the balance between methanol adsorption/oxidation and Pt oxide formation is shifted towards the latter. At very high potentials, the surface is increasingly covered with $\mathrm{PtO}$ and methanol adsorption becomes less favored. ${ }^{50}$

Therefore, the $j-E$ curves at the different temperatures observed in Figure 1 depend on the rate constant of all reaction steps associated with methanol (r1-r4), but also on the surface coverage (variation in the available active area), as well as to the superficial oxidation processes of Pt (r6).

The temperature for oscillatory kinetics is a critical bifurcation parameter, dictating whether or not oscillations will occur in a certain region of the phase space. ${ }^{55}$ Additionally, instead of accessing a global response from all processes occurring in the system, periodic potential oscillations give information on how the increase in rate constants (due to a temperature increase) contributes to, for example, oscillatory frequency ${ }^{30,32,36,37}$ or long-term evolution of the dynamics. ${ }^{32,37}$ Thus, we map the current density region where potential oscillations are sustainable through slow galvanodynamic sweeps (see Supplementary Information, Figure S1) and, subsequently, we carry out galvanostatic experiments. The potential time-series of DMFC at different temperatures are shown in Figure 2. 


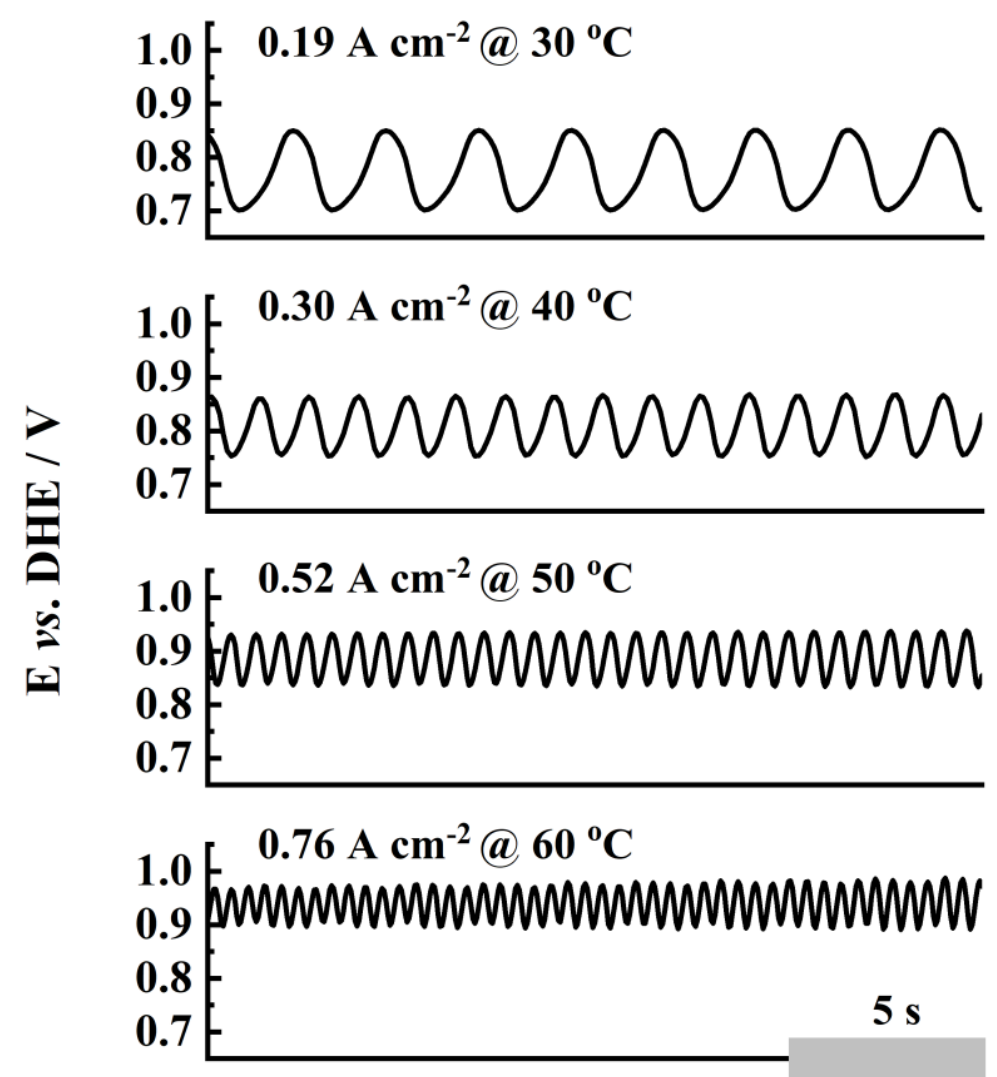

Figure 2. Self-organized potential oscillations for the DMFC at different temperatures. Identical conditions than Figure 1.

In general, regardless of the temperature, we observed only one type of oscillatory pattern: simple and quasi-sinusoidal. ${ }^{19,31,35-37}$ Unlike half-cell studies with massive $\mathrm{Pt}$ electrodes, ${ }^{31,37}$ the oscillations exhibited in Figure 2 are much more robust over time, largely due to the high surface area of gas diffusion electrodes. A slow drift, responsible for driving the system through different oscillatory patterns until the point where oscillations are no longer sustainable, ${ }^{31,56}$ although, inevitably, occurs during the oscillatory operation of the DMFC, it has an insignificant effect on its overall response and the autonomous dynamics presented in Figure 2 can last for hours without significant changes in their profiles.

In turn, concerning frequency and amplitude, the influence of temperature becomes evident. Another point is that the oscillations were not observed at $70{ }^{\circ} \mathrm{C}$. The potential timeseries in Figure 2 shows that as the thermal energy increases, the oscillatory frequency also increases and, as reported by Hartl et al.,${ }^{37}$ there is a gradual decrease in the amplitude of the oscillations (from $0.15 \mathrm{~V}$ at $30^{\circ} \mathrm{C}$ to $0.07 \mathrm{~V}$ at $60{ }^{\circ} \mathrm{C}$ ). This typical Arrhenius behavior in terms of the frequency for the oscillatory electro-oxidation of methanol (the rate constant, $k(T)$, equation 1, is considered to be proportional to the frequency, $\omega(T))$ was first discussed by Carbonio et al. ${ }^{36}$ However, as we will see throughout this paper, an increase in the constant rate 
of a given reaction step does not necessarily imply higher frequencies. ${ }^{30,32,57}$ For example, at high temperatures the oxidation of $\mathrm{CO}_{\mathrm{ad}}$ by oxygenated species of $\mathrm{Pt}(\mathrm{r} 9)$ is favored and this could lead to longer periods of poisoning (and therefore lower frequencies). However, the rate of $\mathrm{CO}_{\mathrm{ad}}$ formation ( $\mathrm{r} 1$ and $\mathrm{r} 2$ ) is also intensified with temperature and this might be the predominant effect on the oscillatory dynamics of methanol electro-oxidation since, in this case, $\omega$ increases with $T$.

Regarding the amplitude decrease, highlighting the increase in the minimum potential reached during the potential cycles, there may have been a change in which reaction path, direct or indirect, is predominant at a given temperature. Hartl et al. ${ }^{37}$ proposed that at low temperatures $\left(T<30^{\circ} \mathrm{C}\right)$ and in polycrystalline $\mathrm{Pt}$, the $\mathrm{CO}_{\mathrm{ad}}$ oxidation has a greater contribution, that is, the indirect path ( $\mathrm{r} 1, \mathrm{r} 2$ and $\mathrm{r} 9)$. At higher temperatures, the direct path, which also includes a Langmuir-Hinshelwood step for the formation of $\mathrm{HCOO}_{\mathrm{ad}}(\mathrm{r} 6)$, would become more representative. An important point is that oscillations at higher temperatures seem to be confined to a potential region richer in adsorbed oxygenated species (at $30{ }^{\circ} \mathrm{C}$ the potential oscillations occur between 0.70 and $0.85 \mathrm{~V}$, while at $60{ }^{\circ} \mathrm{C}$, between 0.90 and $0.97 \mathrm{~V}$ ). Furthermore, as already mentioned, the surface oxidation is also limited by activation (the higher the $T$, the lower the overpotential for the $\mathrm{OH}_{\mathrm{ad}}$ formation, and the greater its coverage at a given potential). ${ }^{52,54}$ Thus, above $60{ }^{\circ} \mathrm{C}$, the isotherms of carbonaceous species $\left(\mathrm{CO}_{\mathrm{ad}}\right.$, $\mathrm{HCOO}_{\mathrm{ad}}$ or $\mathrm{H}_{\mathrm{x}} \mathrm{CO}_{\mathrm{ad}}$ ) and $\mathrm{Pt}$ oxides completely overlap and the electrode is no longer subjected to passivation (when Pt electrode is gradually deactivated) and activation cycles (when electrocatalytic poisons are oxidized by oxides). Also, as the DMFC temperature approaches $100{ }^{\circ} \mathrm{C}$, the faradaic efficiency of methanol electro-oxidation approaches $100 \%$ (all methanol is converted to its final oxidation product, $\left.\mathrm{CO}_{2}\right)^{58}$ and, probably, above a temperature threshold, $60{ }^{\circ} \mathrm{C}$ in this case, the feedback loops collapse ${ }^{17,59,60}$ and we have a linear response.

\subsection{Direct Formic Acid Fuel Cell}

Next, we evaluate the effect exerted by the reaction temperature on a direct formic acid fuel cell, DFAFC, also through linear potential scans between 30 to $70{ }^{\circ} \mathrm{C}$, c.f. Figure 3. The general trend for the DFAFC is similar to that observed in the DMFC. At low potentials, between 0.075 and $0.40 \mathrm{~V}$, the anodic current density is practically zero for all temperatures evaluated. It is assumed that the formic acid electro-oxidation on Pt surface follows a triple mechanism, and strongly depend on acid/base equilibrium (r10): ${ }^{61}$ a direct, fast pathway, through a weakly adsorbed intermediate whose nature is still unknown (r11); the formate pathway (r12); and, finally, the indirect route where $\mathrm{CO}_{\mathrm{ad}}$ is formed (r13). ${ }^{32,34,62}$ 


$$
\begin{gathered}
\mathrm{HCOOH} \rightarrow \mathrm{HCOO}^{-}+\mathrm{H}^{+} \\
\mathrm{HCOO}^{-}+\mathrm{Pt} \rightarrow \mathrm{CO}_{2}+\mathrm{Pt}+\mathrm{H}^{+}+2 \mathrm{e}^{-} \\
\mathrm{HCOOH}+2 \mathrm{Pt} \rightarrow \mathrm{HCOO}_{\mathrm{ad}}+\mathrm{H}^{+}+\mathrm{e}^{-} \rightarrow 2 \mathrm{Pt}+\mathrm{CO}_{2}+\mathrm{H}^{+}+\mathrm{e}^{-} \\
\mathrm{HCOOH}+\mathrm{Pt} \rightarrow \mathrm{CO}_{\mathrm{ad}}+\mathrm{Pt}+\mathrm{H}_{2} \mathrm{O}
\end{gathered}
$$

The temperature independence at $E<0.40 \mathrm{~V}$ is because $\mathrm{HCOOH}$ dehydrates in contact with $\mathrm{Pt}$ surface, producing $\mathrm{CO}_{\mathrm{ad}}(\mathrm{r} 12)$. This species accumulates at low potentials leading to a decrease in the available active sites necessary for the reaction to proceed. That is, although the currents in this potential region are temperature independent, the elementary steps are not: the rate constants of the direct (r11) and formate (r12) pathways increase, as well as the dehydration step (r13), the latter restricts the active area and compromises r11 and r12. ${ }^{63}$

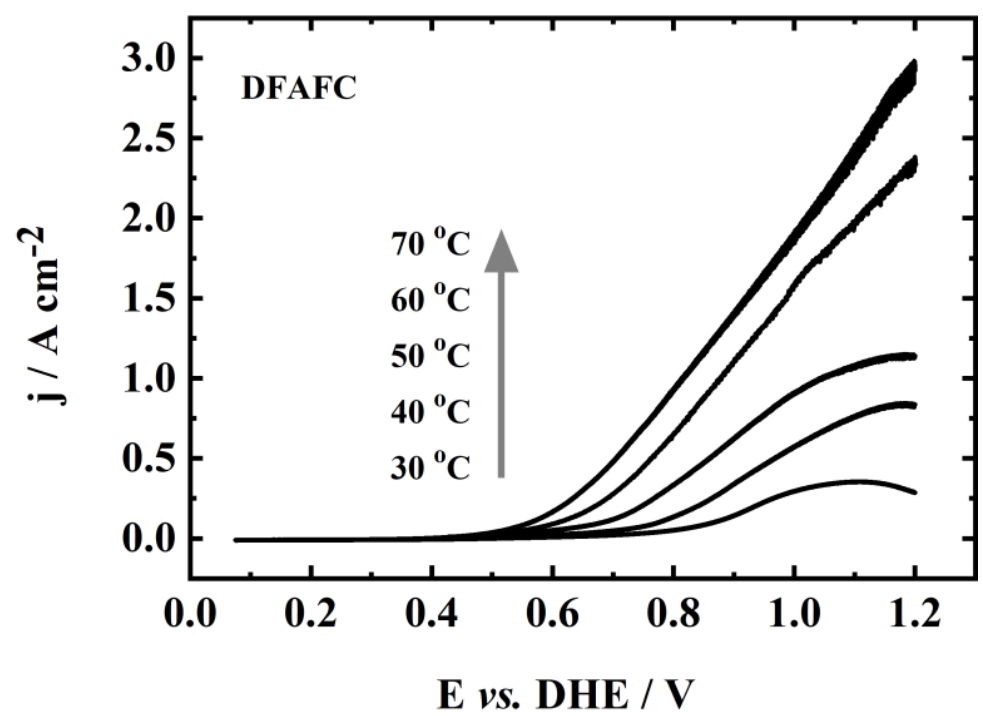

Figure 3. Linear potential sweeps of the DFAFC at different temperatures, ranging from 30 to $70^{\circ} \mathrm{C}$; the gray arrow indicates the direction of the temperature increase. Experimental conditions: anodic and cathodic electrocatalyst $=\mathrm{Pt} / \mathrm{C}\left(1 \mathrm{mg}_{\mathrm{Pt}} \mathrm{cm}^{-2}\right) ;[\mathrm{HCOOH}]=8 \mathrm{~mol} \mathrm{~L}$ 1; fuel flow to the anode $=2 \mathrm{~mL} \mathrm{~min}^{-1} ; \mathrm{H}_{2}$ at the cathode - dynamic hydrogen electrode (DHE), $\mathrm{dE} / \mathrm{dt}=1 \mathrm{mV} \mathrm{s}^{-1}$.

Again, the onset potential is closely associated with the $\mathrm{CO}_{\mathrm{ad}}$ oxidation (r9) through the formation of $\mathrm{Pt}$ oxygenated species ( $\mathrm{r} 5$ ). The temperature increase anticipates the $\mathrm{PtOH}$ formation ( $(\mathrm{r} 5)^{52,54}$ and, in turn, promotes the conversion of $\mathrm{CO}_{\mathrm{ad}}$ to $\mathrm{CO}_{2}(\mathrm{r} 9)$. In these newly released $\mathrm{Pt}$ sites, $\mathrm{HCOOH}$ re-adsorb and its oxidation proceed. ${ }^{62,63}$ This leads to an overpotential decrease of about $0.20 \mathrm{~V}$ when we increase the DFAFC temperature from 30 to $70{ }^{\circ} \mathrm{C}$ 
The onset potential in practical devices, operating with $\mathrm{O}_{2}$ at the cathode, does not depend only on the oxidation and reduction reaction kinetics. It is known that both $\mathrm{CH}_{3} \mathrm{OH}$ and $\mathrm{HCOOH}$ can cross the Nafion membrane towards the cathode in a process called crossover, due to the electro-osmotic drag by proton transport, diffusion triggered by the concentration gradient and/or convection triggered by the pressure gradient between anode and cathode, all of which are facilitated by a temperature increase. ${ }^{64-67}$ These organic molecules at the cathode will react with $\mathrm{O}_{2}$ to form $\mathrm{CO}_{2}$. This implies a fuel cell depolarization due to the consumption of $\mathrm{O}_{2}$ in a reaction other than its reduction and the cathodic electrocatalyst poisoning by carbonaceous intermediates. ${ }^{64}$ That is, the OCP, that is the open circuit potential, of these devices will result from the fuel electro-oxidation and $\mathrm{O}_{2}$ reduction kinetics, the crossover, the ohmic drop, and all these points depend on the temperature.

It is important to highlight that the crossover rate of $\mathrm{CH}_{3} \mathrm{OH}$ is much higher than that of $\mathrm{HCOOH}$ due to the anionic nature of the latter: there is repulsion between the sulfonic groups of $\mathrm{Nafion}^{\circledR}$ and $\mathrm{HCOO}^{-}$anions from the dissociation of $\mathrm{HCOOH}(\mathrm{r} 10) .{ }^{65}$ However, this same characteristic that reduces the $\mathrm{HCOOH}$ permeability through the polymeric electrolyte negatively affects the mass transport through the gas diffusion layer that is hydrophobic because of its composition: Vulcan carbon and polytetrafluoroethylene (PTFE). ${ }^{19,44,67}$ To illustrate this point, Figure 4 shows the linear potential scans of a DMFC and a DFAFC operating at identical

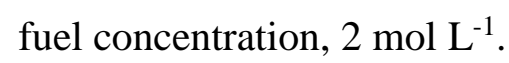

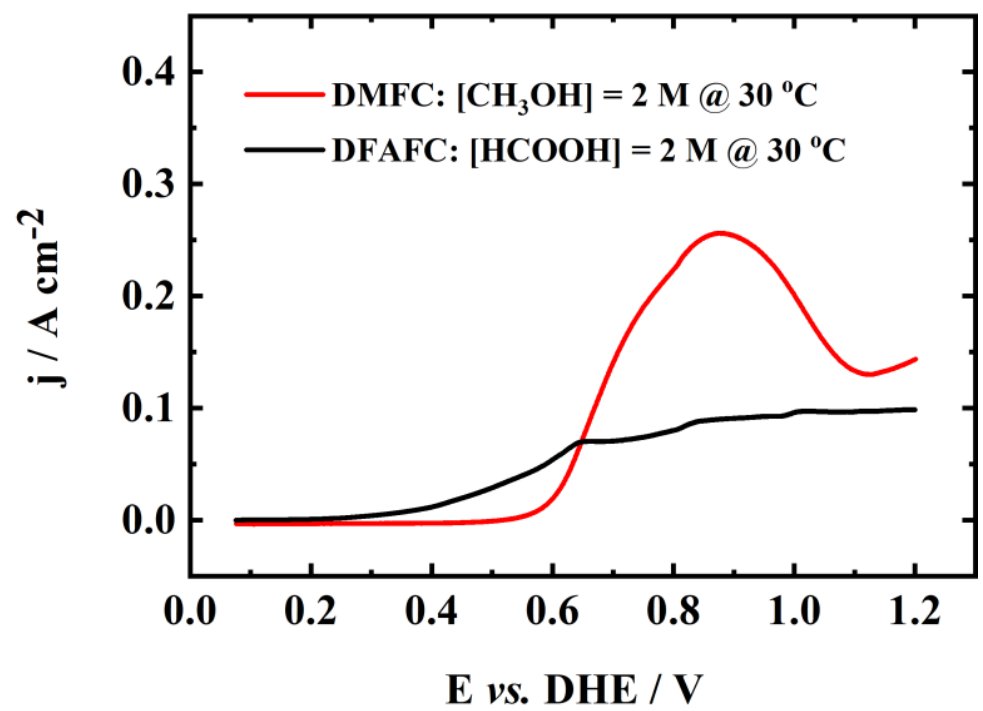

Figure 4. Linear potential sweeps of the DFAFC and the DMFC operating at identical nominal conditions. Experimental conditions: anodic and cathodic electrocatalyst $=\mathrm{Pt} / \mathrm{C}$ $\left(1 \mathrm{mg}_{\mathrm{Pt}} \mathrm{cm}^{-2}\right) ;[\mathrm{HCOOH}]$ or $\left[\mathrm{CH}_{3} \mathrm{OH}\right]=2 \mathrm{~mol} \mathrm{~L}^{-1}$; fuel flow to the anode $=2 \mathrm{~mL} \min ^{-1} ; \mathrm{H}_{2}$ at the cathode - dynamic hydrogen electrode (DHE); $\mathrm{T}=30^{\circ} \mathrm{C} ; \mathrm{dE} / \mathrm{dt}=1 \mathrm{mV} \mathrm{s}^{-1}$. 
For fuel cells operated at relatively low concentrations, $2 \mathrm{~mol} \mathrm{~L}{ }^{-1}$, the current densities at $E>0.60 \mathrm{~V}$ are higher in DMFC than in DFAFC (Figure 4). The opposite trend observed in half-cell studies on massive Pt electrodes, where under similar experimental conditions, currents are higher with formic acid than with methanol. ${ }^{13,68}$ It seems that the DFAFC at $E>0.60 \mathrm{~V}$ reaches a current threshold that has features of diffusional limit, and the onset potential, in this case, is negatively shifted about $0.25 \mathrm{~V}$ compared with the DFAFC fed with $8 \mathrm{~mol} \mathrm{~L}^{-1} \mathrm{HCOOH}$ solution, showing a lower rate of $\mathrm{CO}_{\mathrm{ad}}$ poisoning (r9). To minimize mass transport limitations, we chose to operate the DFAFC at $8 \mathrm{~mol} \mathrm{~L}^{-1}$ (as shown in Figure 3), and also because at this concentration the oscillatory dynamics were more robust over time (at lower concentrations we observed few cycles of damped oscillations), ${ }^{18}$ allowing to extract reproducible frequency and amplitude data.

Zhang and Datta, ${ }^{43}$ evaluated the dynamic behavior of a PEMFC fed with $\mathrm{H}_{2}$ contaminated with $\mathrm{CO}$ and employing $\mathrm{Pt}-\mathrm{Ru} / \mathrm{C}$ as an anodic electrocatalyst, found that temperature is a fundamental factor for the emergence of voltage oscillations, and for the system in question, such dynamics were not observed for temperatures above $80{ }^{\circ} \mathrm{C}$. It is worth mentioning that oscillatory behavior results from very sensitive relationships between rate constants and surface coverages ${ }^{59,60,69}$ and, therefore, will depend strongly on temperature. Thus, employing galvanostatic experiments, the occurrence of potential oscillations in the DFAFC was verified at all temperatures evaluated, with the potential time-series shown in Figure 5. 

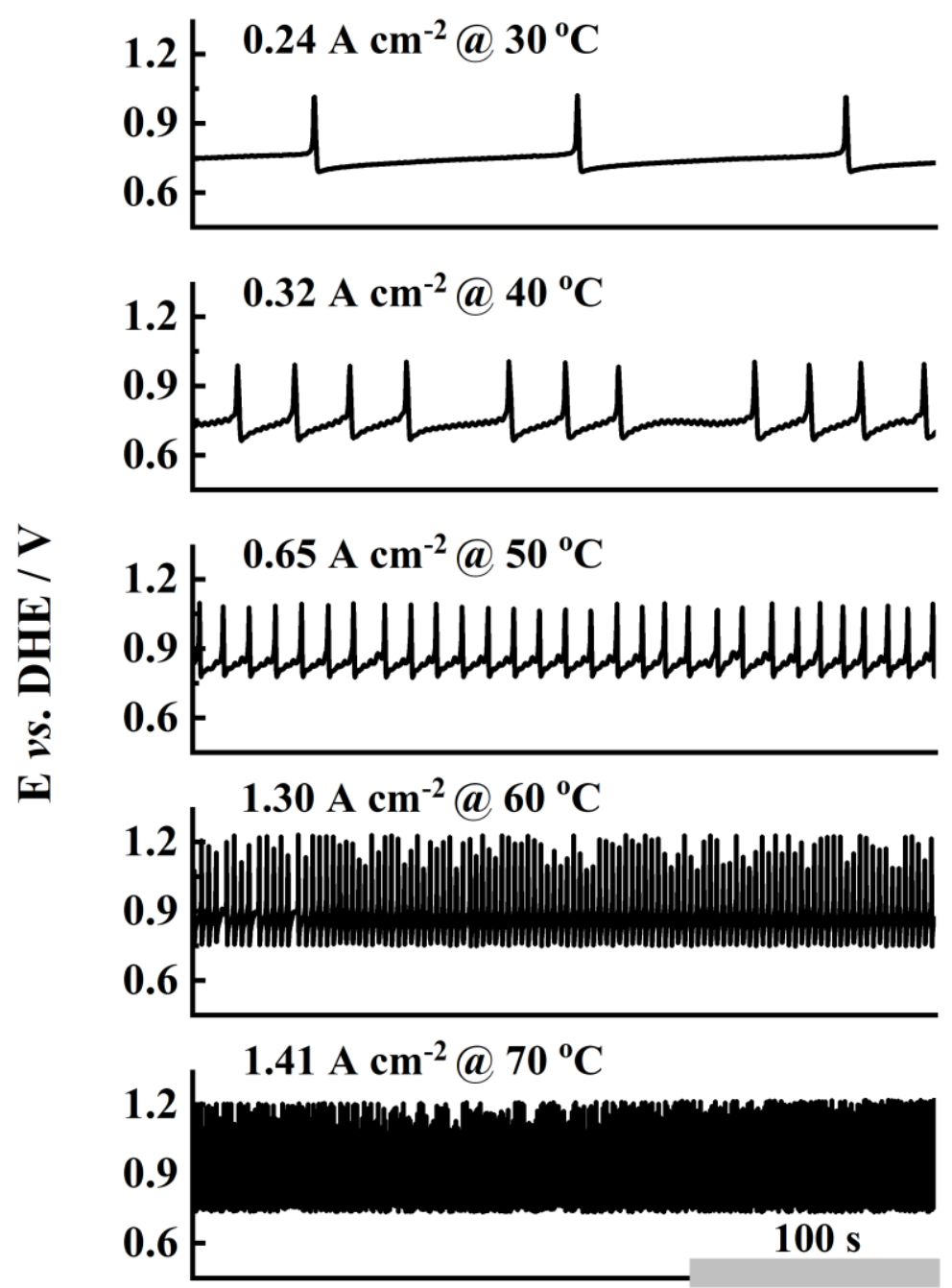

Figure 5. Self-organized potential oscillations for the DFAFC at different temperatures. Identical conditions than Figure 3.

It becomes clear in Figure 5 that as the temperature increases, the oscillatory frequency also increases. Another point to be highlighted is the fact that oscillations occur at temperatures of practical interest for fuel cells and it is the first time that oscillations in DFAFC are obtained at temperatures above $50{ }^{\circ} \mathrm{C} .{ }^{18}$ In general, the oscillation waveform preserves its general characteristics with the temperature increase: a slow increase of the potential followed by an increase and an abrupt fall, then the cycle starts again.

The observation that the oscillatory frequency increases with increasing temperature over the entire temperature range evaluated, from 30 to $70^{\circ} \mathrm{C}$, contrast with the results discussed by Varela and co-workers ${ }^{30,32}$ where they observed a phenomenon called temperature overcompensation. Zülke and Varela ${ }^{32}$ evaluated the temperature effect on the oscillatory electro-oxidation of formic acid and noted that between 5 and $25{ }^{\circ} \mathrm{C}$, assuming the oscillatory frequency to be proportional to the rate constant (equation 1), the system has positive apparent activation energy, while between 25 and $45{ }^{\circ} \mathrm{C}$, it becomes negative. Based on the results 
presented in Figure 5, it is not trivial to point out what may have led to this trend difference, since it is often difficult to bridge the results obtained in half-cell with those obtained in a unit cell. For example, given the large surface area of the electrode used for the DFAFC tests, the deactivation of the surface due to the formation of irreversible Pt oxides can be neglected in the time interval of our experiments, since its effect on the overall response is small. Another point is the capacitance effect. Recently, we estimated the capacitance of the electrical double layer of the electrodes used in our tests: $0.36 \pm 0.02 \mathrm{~F} .{ }^{19}$ By normalizing this value by the electrochemically active area for hydrogen adsorption/desorption, we reach a value of $262 \mu \mathrm{F} \mathrm{cm} \mathrm{cm}^{-2}$, almost 9 times greater than that for polycrystalline $\mathrm{Pt}$ in $0.5 \mathrm{~mol} \mathrm{~L}^{-1} \mathrm{H}_{2} \mathrm{SO}_{4}$ (30 $\left.\mu \mathrm{F} \mathrm{cm}^{-2}\right),{ }^{70}$ largely due to the carbon support. Therefore, the charging time of the double layer has a much more pronounced effect on oscillations in DFAFC than in half-cell. However, as raised by Zülke and Varela, ${ }^{32}$ it is difficult to isolate an elementary step from a network of interrelated reactions and to quantify its contribution to the increase or decrease in frequency with temperature.

\subsection{Direct Ethanol Fuel Cell}

We evaluated a direct ethanol fuel cell (DEFC), specifically the temperature effect, and whether oscillatory kinetics is observed during its operation. Among the fuels evaluated, ethanol is the most attractive for Brazil, ${ }^{71}$ where its large-scale production occurs through sugar cane fermentation. In addition, ethanol has advantages such as it is liquid at room temperature, less toxic than methanol, and renewable. , $^{8,10,72}$

The complete oxidation of ethanol to $\mathrm{CO}_{2}$ involves the transfer of 12 electrons,

$$
\mathrm{CH}_{3} \mathrm{CH}_{2} \mathrm{OH}+3 \mathrm{H}_{2} \mathrm{O} \rightarrow 2 \mathrm{CO}_{2}+12 \mathrm{H}^{+}+12 \mathrm{e}^{-}
$$

while formic acid produces 2 and methanol, 6 electrons. However, the kinetics of ethanol electro-oxidation on Pt is slow and the main products formed are acetaldehyde (r14) and acetic acid (r15), which generate, respectively, 2 and 4 electrons. ${ }^{73-77}$

$$
\begin{gathered}
\mathrm{CH}_{3} \mathrm{CH}_{2} \mathrm{OH} \rightarrow \mathbf{C H} \mathbf{C H O}+2 \mathrm{H}^{+}+2 \mathrm{e}^{-} \\
\mathrm{CH}_{3} \mathrm{CH}_{2} \mathrm{OH}+\mathrm{H}_{2} \mathrm{O} \rightarrow \mathbf{C H}_{3} \mathbf{C O O H}+4 \mathrm{H}^{+}+4 \mathrm{e}^{-}
\end{gathered}
$$

This is because Pt has low efficiency in breaking C-C bonds. An important point is a correlation between the production of $\mathrm{CO}_{2}$ and $\mathrm{CO}_{\mathrm{ad}}$ during ethanol electro-oxidation on Pt: the $\mathrm{CO}_{2}$ formation comes primarily from the oxidative removal of $\mathrm{CO}_{\mathrm{ad}}$ and $\mathrm{H}_{\mathrm{x}} \mathrm{C}_{\mathrm{ad}}$ formed at low potentials directly from ethanol dissociative adsorption. In other words, the formation of $\mathrm{CO}_{\mathrm{ad}}$ 
and, therefore, $\mathrm{CO}_{2}$ does not occur through a soluble intermediate (as in the glycerol electrooxidation on platinum). ${ }^{76}$

The increase in temperature during ethanol electro-oxidation on carbon-dispersed $\mathrm{Pt}$ electrodes, in turn, considerably increases the selectivity for $\mathrm{CO}_{2}$. For example, Sun et al. ${ }^{78}$ showed by means of an electrochemical cell (adapted for high temperatures and pressure) coupled to a mass spectrometer (on line Differential Electrochemical Mass Spectrometry, DEMS) that the complete oxidation of ethanol to $\mathrm{CO}_{2}$ reaches $90 \%$ at high temperatures, low concentration and relatively low potentials $\left(100{ }^{\circ} \mathrm{C}, 0.01 \mathrm{~mol} \mathrm{~L}^{-1}\right.$ ethanol and $\left.0.48 \mathrm{~V}\right)$. An increase in concentration and a decrease in temperature imply a lower $\mathrm{CO}_{2}$ formation rate under ambient conditions $\left(1.6 \%\right.$ at $23{ }^{\circ} \mathrm{C}, 0.1 \mathrm{~mol} \mathrm{~L}^{-1}$, and $\left.0.68 \mathrm{~V}\right)$. In this direction, we performed linear potential sweeps in a DEFC operating at different temperatures; results are shown in Figure 6.

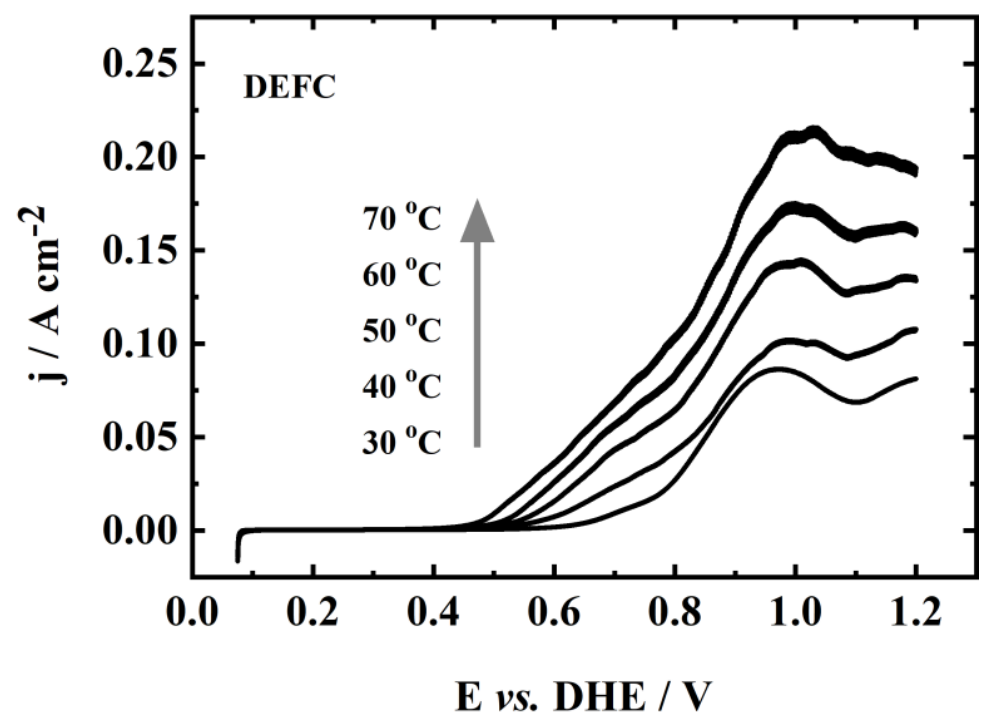

Figure 6. Linear potential sweeps of the DEFC at different temperatures, ranging from 30 to $70{ }^{\circ} \mathrm{C}$; the gray arrow indicates the direction of the temperature increase. Experimental conditions: anodic and cathodic electrocatalyst $=\mathrm{Pt} / \mathrm{C}\left(\begin{array}{llll}\mathrm{mg}_{\mathrm{Pt}} & \mathrm{cm}^{-2}\end{array}\right)$; $\left[\mathrm{CH}_{3} \mathrm{CH}_{2} \mathrm{OH}\right]=2 \mathrm{~mol} \mathrm{~L}^{-1}$; fuel flow to the anode $=2 \mathrm{~mL} \mathrm{~min}^{-1} ; \mathrm{H}_{2}$ at the cathode - dynamic hydrogen electrode (DHE), $\mathrm{dE} / \mathrm{dt}=1 \mathrm{mV} \mathrm{s}^{-1}$.

It can be seen in Figure 6 that the onset potential for ethanol electro-oxidation decreases by about $0.20 \mathrm{~V}$ when the temperature increases from 30 to $70{ }^{\circ} \mathrm{C}$. At low potentials, as observed for methanol and formic acid, the reaction is inhibited due to the formation of strongly adsorbed intermediates, such as $\mathrm{CO}_{\mathrm{ad}}$ and $\mathrm{H}_{\mathrm{x}} \mathrm{C}_{\mathrm{ad}}$, from the dissociative adsorption of ethanol on $\mathrm{Pt}^{76}$ Above $0.45 \mathrm{~V}$, Pt oxide formation leads to the oxidation of these adsorbates and the current 
increase. An interesting aspect is the presence of a current peak at about $1.00 \mathrm{~V}$ and a shoulder between 0.60 and $0.80 \mathrm{~V}$.

From in situ Fourier transform infrared spectroscopy in an attenuated total reflection configuration (ATR-FTIRS) it is known that the acetate absorption band is observed above $\approx 0.70 \mathrm{~V}$ (room temperature), same potential in which oxidation current starts to flow and the $\mathrm{CO}_{\mathrm{ad}}$ absorption band starts to decrease. ${ }^{77}$ That is, $\mathrm{CH}_{3} \mathrm{COO}_{\mathrm{ad}}$ formation begins as soon as $\mathrm{CO}_{\mathrm{ad}}$ starts to be oxidized and free sites are released. This differentiation in two peaks that we see in Figure 6 may be due to currents from the oxidative removal of $\mathrm{CO}_{\mathrm{ad}}$, the first process, followed by the production of acetic acid.

It is noteworthy that acetic acid is not oxidized at mild temperatures (even at $250{ }^{\circ} \mathrm{C}$ the oxidation current observed for $\mathrm{CH}_{3} \mathrm{COOH}$ on $\mathrm{Pt}$ are small) ${ }^{79}$ and, therefore, is a stable final product. Once formed, it ends up acting as a specifically adsorbed anion, limiting the number of free sites for the reaction to proceed..$^{77}$ This highlights the need for electrocatalysts with greater selectivity for $\mathrm{CO}_{2}$ and/or the operation of DEFC at temperatures above $90{ }^{\circ} \mathrm{C}$.

Like methanol and formic acid, the occurrence of oscillatory dynamics during electrooxidation of ethanol has also been reported in the literature. ${ }^{13,33,38,39,80}$ In practical systems, there is apparently only one study that mentions the existence of oscillations during the electrochemical reform of ethanol in a proton exchange membrane electrolyzer, but the authors do not explore the phenomenon. ${ }^{81}$ To assess the emergence of oscillatory dynamics during the DEFC operation, similar to the previous one, we map the current region where potential oscillations occur through slow current sweeps (Figure S1c) and then we obtained the potential time-series at a constant current density. The results are given in

\section{Figure 7.}

An intrinsic feature of the DEFC is that the oscillatory dynamics only take place when the system leaves a high current density to a lower one (from high to low potential values) during the slow current sweeps, this hysteresis was not observed in DMFC and DFAFC, see Supplementary Information Figure S1c. This aspect is interesting, since in the works of Wang et $a l .{ }^{73}$ and Cantane et $a l .{ }^{74}$ during the reverse scan of cyclic voltammetry the mass fragment referring to $\mathrm{CO}_{2}$ measured by DEMS does not present ionic current. Therefore, the breaking of the $\mathrm{C}-\mathrm{C}$ bond only occurs at significant rates at potentials below $0.40 \mathrm{~V}$, which is when the oxidation currents in the negative direction are inhibited (Pt oxides are reduced), in addition to being a very slow process at temperatures below $40{ }^{\circ} \mathrm{C} .{ }^{78}$ 
This is an indication that other catalytic poisons, in addition to $\mathrm{CO}_{\mathrm{ad}}$, may be involved in the emergence of oscillatory kinetics during ethanol electro-oxidation. In fact, when monitoring the absorption bands of $\mathrm{CO}_{\mathrm{ad}}\left(\theta_{\mathrm{CO}}\right)$ and carbonyl species (such as acetaldehyde and acetic acid, $\theta_{\mathrm{C}=0}$ ) on Pt by ATR-FTIRS during oscillatory electro-oxidation of ethanol, Silva et $a l .{ }^{39}$ observed that over a time-series the $\theta_{\mathrm{CO}}$ decreases and that even within negligible values, the oscillations persist. In turn, while $\theta_{\mathrm{CO}}$ falls, $\theta_{\mathrm{C}=\mathrm{O}}$ gradually increases. This demonstrates that $\mathrm{CO}_{\mathrm{ad}}$ is not the only electrocatalytic poison that must be considered during the ethanol electrooxidation. The authors proposed that the accumulation of $\mathrm{CH}_{3} \mathrm{COO}_{\mathrm{ad}}$ can pronounce the effect of CO adsorption/oxidation, and, therefore, even in very low amounts, this intermediate can maintain oscillations over time. This might helps us to understand why potential oscillations during the electro-oxidation of ethanol only occur when the electrode leaves an active (high potentials promote the formation of acetic acid) to a passive (blocked electrode surface) condition. When the system evolves from low to higher potential values, the adsorbed ethanol gradually dissociates, forming $\mathrm{CO}_{\mathrm{ad}}$, increasing its coverage. ${ }^{39,76}$ However, a high $\theta_{\mathrm{CO}}$ may not be the only criterium to promote autonomous periodic oscillations. Since the potential is high enough to activate water molecules and form $\mathrm{PtOH}(\mathrm{r} 5), \mathrm{CO}_{\mathrm{ad}}$ starts being oxidized (r9), but to oscillations emerge, $\mathrm{CO}_{\mathrm{ad}}$ must be gradually replaced, to a new cycle starts over. But as the potential is carried up by the current increase, $\theta_{\mathrm{CO}}$ drops to zero and the break of C-C on ethanol is unfavored (above $0.70 \mathrm{~V} \theta_{\mathrm{CO}}$ decreases and $\theta_{\mathrm{C}=\mathrm{O}}$ increases, as mentioned), ${ }^{77}$ and no kinetic dynamic is observed during the forward current scan. Only during the backward current scan, when the system leaves a high towards lower potential values, the electrode surface is free from $\mathrm{CO}_{\mathrm{ad}}$ at the beginning and there is the formation of acetic acid (that once adsorbed can remain on Pt surface at $E<1.1 \mathrm{~V}) .{ }^{77}$ As the potential gradually decreases, $\mathrm{CO}$ formation can take place (even at a very small extend), ${ }^{39}$ giving rise to the conditions required for potential oscillations during ethanol electro-oxidation.

\section{Returning to}

Figure 7, it is observed that the potential oscillations during ethanol electro-oxidation lie between 0.45 and $0.75 \mathrm{~V}$, and these values do not vary significantly with temperature. When looking at the linear potential scans in Figure 6, it is noted that the potential interval in which the dynamics occur coincides with the first oxidation process, the shoulder that precedes the current peak. Moreover, during each cycle the potential remains longer at high values than at low values, a pattern similar to that observed in half-cell both in alkaline, ${ }^{38}$ and acid media. ${ }^{39}$ An important point is that oscillatory behavior was observed only at 30,40 , and $50{ }^{\circ} \mathrm{C}$. Although 
during the galvanodynamic scans, Figure S1c, we observed some potential spikes at 60 and $70 \mathrm{C}$, the DEFC at these temperatures did not show robust oscillations over time. The fact that oscillatory kinetics is only observed at $T \leq 50{ }^{\circ} \mathrm{C}$ (in DMFC such dynamic behavior occurred at $T \leq 60{ }^{\circ} \mathrm{C}$, while in DFAFC, at $T \leq 70{ }^{\circ} \mathrm{C}$ ) is probably associated with the interrelation among the potential-dependent adsorption isotherms of $\mathrm{CO}$, acetate and oxygenated species. Along a time-series, $\theta_{\mathrm{CO}}$ decreases and $\theta_{\mathrm{C}=\mathrm{O}}$ increases, with periodic changes in potential being maintained by a very small amount of $\mathrm{CO}_{\mathrm{ad}}$ that is found in a limited electrode area not yet covered by $\mathrm{CH}_{3} \mathrm{COO}_{\mathrm{ad}} .{ }^{39}$ Probably, above $50{ }^{\circ} \mathrm{C}$, the processes involving the formation of $\mathrm{CO}_{\mathrm{ad}}$ and its oxidation become so fast that oscillations cease.

Now, in terms of oscillatory frequency, it is noted that the temperature effect for the electro-oxidation of ethanol is quite different from that observed for methanol and formic acid. At $30{ }^{\circ} \mathrm{C}$ the average frequency is $\approx 0.004 \mathrm{~Hz}$, at $40{ }^{\circ} \mathrm{C}$ it is $\approx 0.005 \mathrm{~Hz}$, and at $50{ }^{\circ} \mathrm{C}$, $\approx 0.002 \mathrm{~Hz}$. Since the periods shown in

Figure 7 do not present a clear trend, we can assume that the oscillation frequency in DEFC is less sensitive to changes in temperature. However, when looking at Figure 6, it is noted that an increase in temperature leads to an increase in current; in other words, an increase in the reaction kinetic constants (equation 1). 

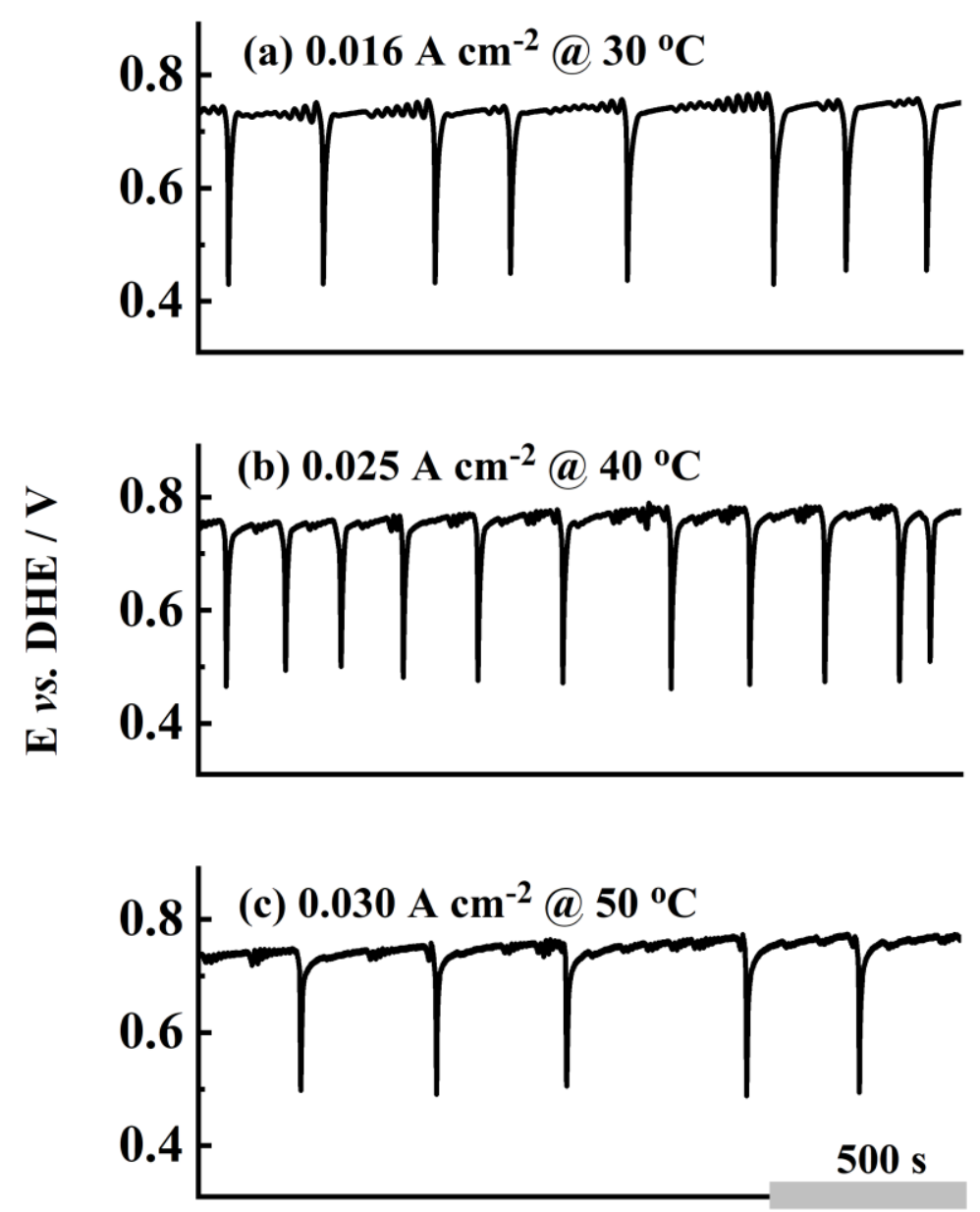

Figure 7. Self-organized potential oscillations for the DEFC at different temperatures. Identical contitions than that of Figure 6.

The activation energy in electrochemical processes depends mainly on (i) the electrode potential; (ii) the reaction pathways accessed in this potential; and (iii) the coverage of the adsorbed intermediates, such as $\mathrm{CO}_{\mathrm{ad}}$, oxygenated species, and anions. ${ }^{52,63}$ The complex reaction mechanism of ethanol electro-oxidation, which involves the transfer of 12 electrons and goes through several intermediates, can have steps that contribute negatively to the increase in the oscillatory frequency with the temperature increase. For example, an increase in desorption constants or even in the oxidation rate of $\mathrm{CO}_{\mathrm{ad}}$ with temperature implies lower rates of electrode poisoning, leading to an increase in the period (or decrease in frequency). Concomitantly, the rate of formation of this catalytic poison increases proportionally with temperature and the frequency is not changed. There are, of course, several coupled processes that can result in an increase or decrease in frequency. Non-Arrhenius behavior in oscillatory systems (temperature compensation or overcompensation) does not mean that the kinetic constants of each reaction step do not depend on temperature, but that their role and/or weight in the oscillatory frequency changes. Thus, similar to that observed during the oscillatory 
electro-oxidation of ethylene glycol, ${ }^{57}$ during the ethanol electro-oxidation different reaction steps may contribute differently to the dependence of the oscillatory frequency on temperature, compensating each other, so that it is not statistically affected, as observed in

\section{Figure 7.}

\subsection{Direct Dimethyl Ether Fuel Cell}

An ethanol isomer that has also been quoted for direct use in fuel cells is dimethyl ether (DME), $\mathrm{CH}_{3} \mathrm{OCH}_{3} .{ }^{9}, 10$ This molecule has numerous applications in the industry, being widely used as compressed gas for propellant in aerosols and as a refrigerant. ${ }^{82}$ It is produced, usually, in a two-step process: synthesis gas is converted to methanol, and methanol is dehydrated to dimethyl ether. ${ }^{83}$ Since synthesis gas can be obtained through biomass, its use is justified in devices that are intended to be less harmful to the environment. Besides, DME i) is less toxic than methanol; ii) presents a slower crossover rate because its lower dipole moment compared to methanol and ethanol; and iii) does not require breaking the $\mathrm{C}-\mathrm{C}$ bond, a challenge in electrocatalysis for the use of molecules with more than one carbon. ${ }^{82,84}$

Similarly to DMFC, DFAFC, and DEFC, we evaluated the temperature effect during the electro-oxidation of dimethyl ether in a DDMEFC (Direct Dimethyl Ether Fuel Cell) by linear potential scans, as shown in

Figure 8. Like the other organic molecules, at low potentials, the oxidation currents are very small and the DME electro-oxidation only occurs at relevant rate upon the formation of $\mathrm{Pt}$ oxygenated species. There is a decrease in the anodic overpotential, $\approx 0.10 \mathrm{~V}$, when the temperature increases from 30 to $70{ }^{\circ} \mathrm{C}$. In terms of current density, from 30 to $60{ }^{\circ} \mathrm{C}$, the peak current at $\approx 0.75 \mathrm{~V}$ undergoes a 4-fold increase. 


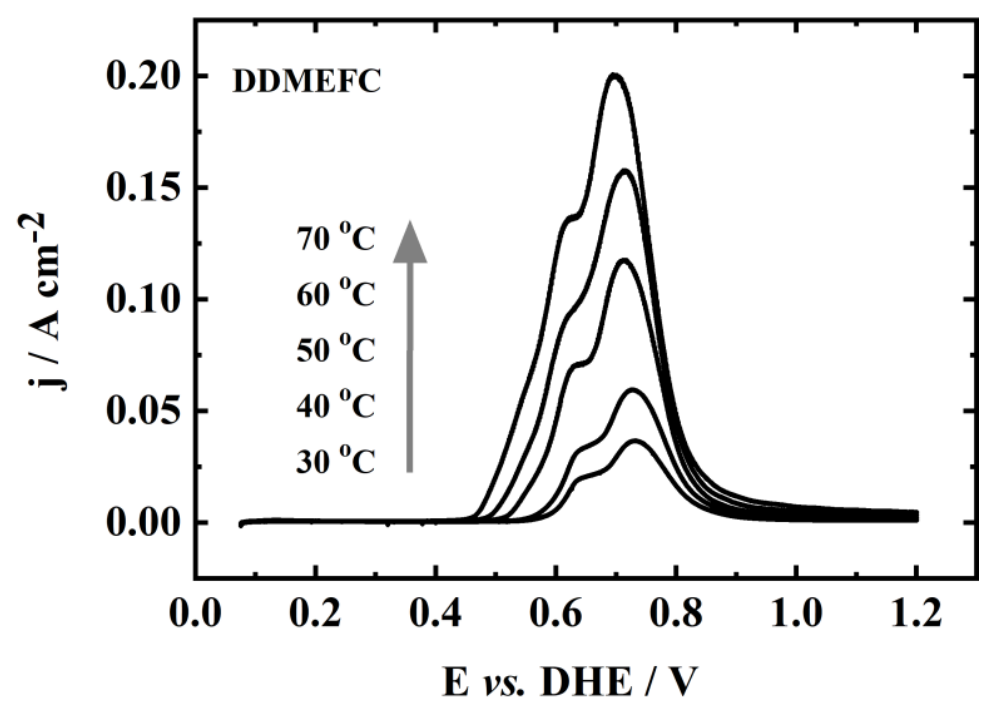

Figure 8. Linear potential sweeps of the DDMEFC at different temperatures, ranging from 30 to $70^{\circ} \mathrm{C}$; the gray arrow indicates the direction of the temperature increase. Experimental conditions: anodic and cathodic electrocatalyst $=\mathrm{Pt} / \mathrm{C}\left(\begin{array}{llll}1 & \mathrm{mg}_{\mathrm{Pt}} & \mathrm{cm}^{-2}\end{array}\right)$; $\left[\mathrm{CH}_{3} \mathrm{OCH}_{3}\right] \approx 1.6 \mathrm{~mol} \mathrm{~L}^{-1}$ (saturated aqueous solution); fuel flow to the anode $=2 \mathrm{~mL} \mathrm{~min}$ ${ }^{1} ; \mathrm{H}_{2}$ at the cathode - dynamic hydrogen electrode (DHE), $d E / d t=1 \mathrm{mV} \mathrm{s}^{-1}$.

It is worth noting that the results presented in

Figure 8 were obtained by saturating water with DME at room temperature $\left(\approx 25^{\circ} \mathrm{C}\right)$, originating a solution with a concentration of about $1.65 \mathrm{~mol} \mathrm{~L}^{-1}, 45$ and the anode of this device was not pressurized. Therefore, once the DME solution from the reservoir comes into contact with the heated cell, a two-phase system is formed: gaseous DME and a solution with a concentration lower than the initial one. ${ }^{84,85} \mathrm{We}$ chose to work in these conditions because the fuel management in a liquid phase is simpler, to maintain a certain correspondence with the results obtained for DMFC, DFAFC, and DEFC, and because there are reports that the performance of the DDMEFC fed with DME in aqueous solution is about twice as high as in the gas phase. ${ }^{84}$ The main point is that the pressure in DDMEFC plays a role as important as the temperature, ${ }^{84}$ and that the DME concentration in the aqueous phase at the membrane electrode assembly is different from that in the reservoir.

Figure 8 shows two oxidation peaks, a well-defined shoulder at $0.65 \mathrm{~V}$ and a current peak at $0.73 \mathrm{~V}$, at $30{ }^{\circ} \mathrm{C}$. As the temperature rises, both are slightly shifted to lower potentials. Although the DME electro-oxidation mechanism has many gaps, likely successive dehydrogenations will occur on $\mathrm{Pt}$, the breakage of the $\mathrm{C}-\mathrm{O}$ bond, and the formation of $\mathrm{CO}_{\mathrm{ad}}$ and $\mathrm{CH}_{\mathrm{x}, \mathrm{ad}}$. Some steps have been proposed: ${ }^{86-89}$ 


$$
\begin{aligned}
\mathrm{CH}_{3} \mathrm{OCH}_{3}+\mathrm{Pt} & \rightarrow \mathrm{CH}_{3} \mathrm{OCH}_{2, \mathrm{ad}}+\mathrm{H}^{+}+\mathrm{e}^{-} \\
\mathrm{CH}_{3} \mathrm{OCH}_{2, \mathrm{ad}}+2 \mathrm{Pt} & \rightarrow \mathrm{CH}_{3} \mathrm{OC}_{\mathrm{ad}}+2 \mathrm{H}^{+}+2 \mathrm{e}^{-} \\
\mathrm{CH}_{3} \mathrm{OC}_{\mathrm{ad}}+2 \mathrm{Pt} & \rightarrow \mathrm{CHOC}_{\mathrm{ad}}+2 \mathrm{H}^{+}+2 \mathrm{e}^{-} \\
\mathrm{CH}_{3} \mathrm{OC}_{\mathrm{ad}}+\mathrm{H}_{2} \mathrm{O} & \rightarrow \mathrm{HCO}_{\mathrm{ad}}+\mathrm{CH}_{3} \mathrm{OH} \\
\mathrm{HCO}_{\mathrm{ad}} & \rightarrow \mathrm{CO}_{\mathrm{ad}}+\mathrm{H}^{+}+\mathrm{e}^{-} \\
\mathrm{CHOC}_{\mathrm{ad}} & +\mathrm{Pt} \rightarrow \mathrm{CO}_{\mathrm{ad}}+\mathrm{CH}_{\mathrm{ad}} \\
\mathrm{CH}_{\mathrm{ad}}+\mathrm{OH}_{\mathrm{ad}} & \rightarrow \mathrm{Pt}+\mathrm{CO}_{\mathrm{ad}}+2 \mathrm{H}^{+}+2 \mathrm{e}^{-}
\end{aligned}
$$

The first steps of dehydrogenation (r17 and r18) resemble that of methanol and require at least three adjacent Pt sites on (111) domains. ${ }^{90}$ However, the interaction of DME with the Pt surface is less intense compared to methanol, ${ }^{45}$, which is reflected in the large difference in current density between both cases: at $30{ }^{\circ} \mathrm{C}$ and $0.70 \mathrm{~V}, 0.15 \mathrm{~A} \mathrm{~cm}^{-2}$ for DMFC (Figure 1), while $0.03 \mathrm{~A} \mathrm{~cm}^{-2}$ for DDMEFC (

Figure 8). The difference in concentration at $30{ }^{\circ} \mathrm{C}\left(\left[\mathrm{CH}_{3} \mathrm{OH}\right]=2 \mathrm{~mol} \mathrm{~L}^{-1}\right.$ and $\left[\mathrm{CH}_{3} \mathrm{OCH}_{3}\right] \approx 1.6 \mathrm{~mol} \mathrm{~L}^{-1}$ ) is not sufficient to explain this discrepancy. This is because the second methyl group in $\mathrm{CH}_{3} \mathrm{OCH}_{3}$ stabilizes the $\mathrm{C}$ - $\mathrm{H}$ bonds, making them less reactive than in $\mathrm{CH}_{3} \mathrm{OH}^{4}{ }^{45}$

The first fragment adsorbed from the DME, $\mathrm{CH}_{3} \mathrm{OCH}_{2, \mathrm{ad}}(\mathrm{r} 13)$, and $\mathrm{CO}_{\mathrm{ad}}$ have already been detected by in situ FTIR. ${ }^{88}$ Based on the presented results, one can note the ubiquity of a catalytic poison, usually $\mathrm{CO}_{\mathrm{ad}}$, underling the emergence of oscillatory kinetics during the electro-oxidation of small organic molecules. ${ }^{12,13,18,19,27-41}$ This is the case for DMFC, DFAFC, and DEFC, with the latter still having the participation of $\mathrm{CH}_{3} \mathrm{COO}_{\mathrm{ad}}$ that reverberates the effect of $\mathrm{CO}_{\mathrm{ad}}{ }^{39}$ Although there are no reports of oscillatory kinetics during DME electro-oxidation, the steps described between r17 to r23, lead us to assume that such dynamic is in principle possible in DDMEFC. Therefore, we evaluated DDMEFC under galvanostatic control to map the current region where potential oscillations could occur, results are given in

Figure 9. 

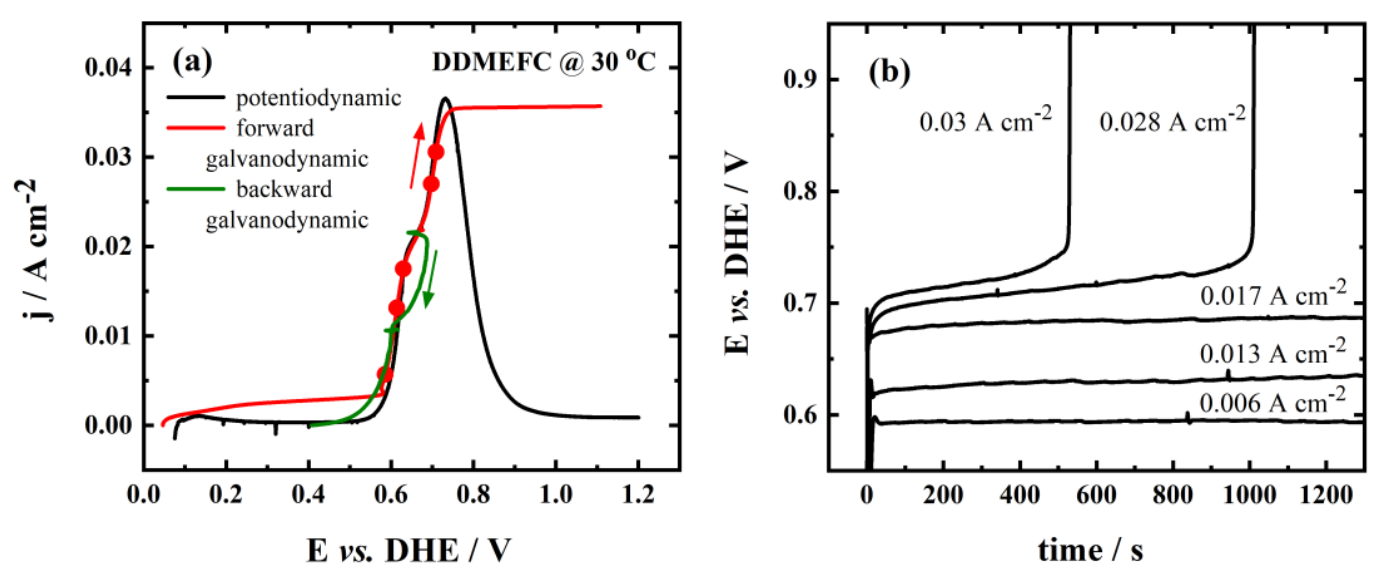

Figure 9. (a) Forward (red curve) and backward (green curve) galvanodynamic sweeps of the DDMEFC at $17 \mu \mathrm{A} \mathrm{cm}^{-2} \mathrm{~s}^{-1}$; for comparison, the potentiodynamic sweep at $30{ }^{\circ} \mathrm{C}$ is presented again. (b) Potential time-series of the DDMEFC operating at different current densities, the red dots in (a) show the exact region of the oxidation peak where these current densities lie. Same conditions as Figure 8.

Note that during the forward galvanodynamic sweep,

Figure $9 \mathbf{a}$, the potential and the current are monotonically correlated. When the required current exceeds its peak value, the DME electro-oxidation is insufficient to maintain it, and, therefore, the potential increases rapidly to the region of oxygen evolution reaction. As performed with DEFC, we also evaluated backward current scanning. However, in this case, we also do not observe periodic potential oscillations. Finally, potential time-series at different current densities are presented in

Figure 9b. Chronopotentiometry was carried out to confirm whether, after a long induction period, not contemplated during a galvanodynamic sweep, there is autonomous dynamic behavior. As we can see, even after $1200 \mathrm{~s}$ at different current densities, the anodic potential of DDMEFC remains stable.

As the interaction of the DME with the Pt surface is less intense compared to the other examples discussed here $\left(\mathrm{CH}_{3} \mathrm{OH}, \mathrm{HCOOH} \text {, and } \mathrm{CH}_{3} \mathrm{CH}_{2} \mathrm{OH}\right)^{45,89}$ the reaction step or pathway responsible for the major current supply (current carrier) during oscillations is insufficient, it occurs at a very small rate. Therefore, the absence of oscillatory kinetics during DME electrooxidation might be attributed to a lack of a step that keeps the required current while the electrode is gradually poisoned by $\mathrm{CO}_{\mathrm{ad}}$. Error! Bookmark not defined. However, a broader mapping is needed; for example, a primordial point would be the management of the gas phase within the DDMEFC anode, evaluating if a facilitated mass transport through the gas diffusion electrodes would enable such dynamic. 
To better explore the mechanisms behind the emergence of oscillatory dynamics during the electro-oxidation of organic molecules, in the next section we will evaluate the four fuel cells covered in this article - DMFC, DFAFC, DEFC and DDMEFC - by means of electrochemical impedance spectroscopy. Finally, we provide an overview, showing how autonomous periodic dynamics in fuel cells can help in understanding the processes occurring in these devices.

\subsection{Electrochemical Impedance Spectroscopy}

The origin of instabilities in electrochemical systems is associated with a region on the polarization curve where an increase in the electrode potential leads to a decrease in the current, that is, even increasing the energy of the system, the reaction does not occur at higher rates. In other words, there is a Negative Differential Resistance (NDR) region. There is a range of work on the origin of bistability and oscillatory kinetics, ${ }^{14,55,69,91,92}$ but here we will restrict ourselves to practical concepts, such as the use of the electrochemical impedance spectroscopy technique (EIS, Electrochemical Impedance Spectroscopy) ${ }^{12,32,40,57,60,91,92}$ to locate in which region of the $j-E$ curve transitions from a stationary to an oscillatory state can occur. This will help us understand why methanol and formic acid have robust potential oscillations that remain until 60 and $70{ }^{\circ} \mathrm{C}$, respectively, while ethanol has its dynamics restricted to a small current window, and dimethyl ether did not exhibit oscillatory kinetics.

Basically, the EIS applied to stability analysis is based on the resonance between the dynamic behavior of the electrical circuit components and an alternating current (AC) sinusoidal disturbance. ${ }^{91}$ Once the resonance occurs, the impedance of the system versus the external disturbance equals zero and the signal produced does not present any phase change. ${ }^{91}$ It is worth noting that an EIS spectrum covering a wide range of frequencies must be capable of linearization throughout its domain and for that, it must be stable. Linearity is guaranteed using AC disturbances of small amplitudes and by asymptotic stability, the latter is the return to the initial steady-state when the external stimulus is removed. ${ }^{91,92}$ Thus, when dealing with non-linear and unstable systems, such as the electro-oxidation of some organic molecules, the IES analyses must be carried out under conditions in which the steady-state is maintained over time. It is noted that the polarization curves for fuel cells evaluated here (Figure1, 3, 6, and Figure 8) are stable under potentiostatic control: for each potential, there is only one associated current value. In fact, it is known from previous studies that the electro-oxidation of most small organic molecules is classified as HN-NDR oscillators (Hidden N-shaped Negative Differential Resistance). ${ }^{12,18,19,28,32,40,57,60,91}$ Basically, this class of electrochemical 
oscillators is characterized by an $\mathrm{N}$-shaped $j-E$ curve that is partially hidden at low potentials due to adsorbates that inhibit the reaction to continue. ${ }^{59,60,91,92}$ In other words, a fast reaction step that otherwise could occur freely is masked/hidden at DC conditions by a slow step that forms a strongly adsorbed intermediate, a catalytic poison. These systems show current and potential oscillations. Under potentiostatic control mode, current oscillations occur only above certain ohmic drop threshold that can be reached coupling an external resistance between the working electrode and the potentiostat; the galvanostatic mode can be reduced to a limiting situation where the external resistance tends to infinity. ${ }^{14, E r r o r ! ~ B o o k m a r k ~ n o t ~ d e f i n e d ., ~} 91$

Although EIS measurements must be performed in a steady-state, the spectra indicate where the system will undergo qualitative transitions or bifurcations. Qualitatively and directly, this happens whenever the curve on the Nyquist graph assumes a purely real value, intercepting the abscissa axis in its negative branch (negative differential resistance). There are two situations: the first, if $Z=0$ for a non-zero frequency, $\omega \neq 0$, we have a Hopf bifurcation. This $\omega \neq 0$ is known as Hopf frequency $\left(\omega_{H}\right)$ and occurs at the very beginning of the oscillatory behavior. The second is known as saddle-node bifurcation and occurs when $Z=0$ for $\omega \rightarrow 0$. The latter is associated with bistability/hysteresis. ${ }^{91,92}$

We evaluated the electro-oxidation of methanol, formic acid, ethanol, and dimethyl ether in a fuel cell arrangement employing EIS to point out the potential region in which negative differential resistance manifests itself. In Error! Reference source not found. we present the impedance spectra obtained at different potentials for DMFC and DFAFC.

Note that at low potentials, $E \leq 0.6 \mathrm{~V}$ and $E \leq 0.5 \mathrm{~V}$ for DMFC (Error! Reference source not found.a) and DFAFC (Error! Reference source not found.b), respectively, the real part of impedance assumes only positive values, which indicates a region stable. If we apply very low currents during galvanostatic experiments, the electrode potential assumes a low stationary value, with high intermediate coverage that prevents oscillatory kinetics. However, as we increase the potential, the HN-NDR profile manifests itself (red spectra). Comparing the Nyquist plots with the polarization curves of both cells, the HN-NDR nature is evident, since, in the potential where such spectra were obtained, the slope of the $j$ - $E$ curve is positive (an increase in $E$ implies an increase in $j$ ), meaning that the negative differential resistance observed in the spectra is related to a process that is partially hidden due to a catalytic poison that adsorbs at low potentials (the indirect pathway of both methanol and formic acid forms $\mathrm{CO}_{\mathrm{ad}}$, that blocks active surface sites where the direct route would occur). 


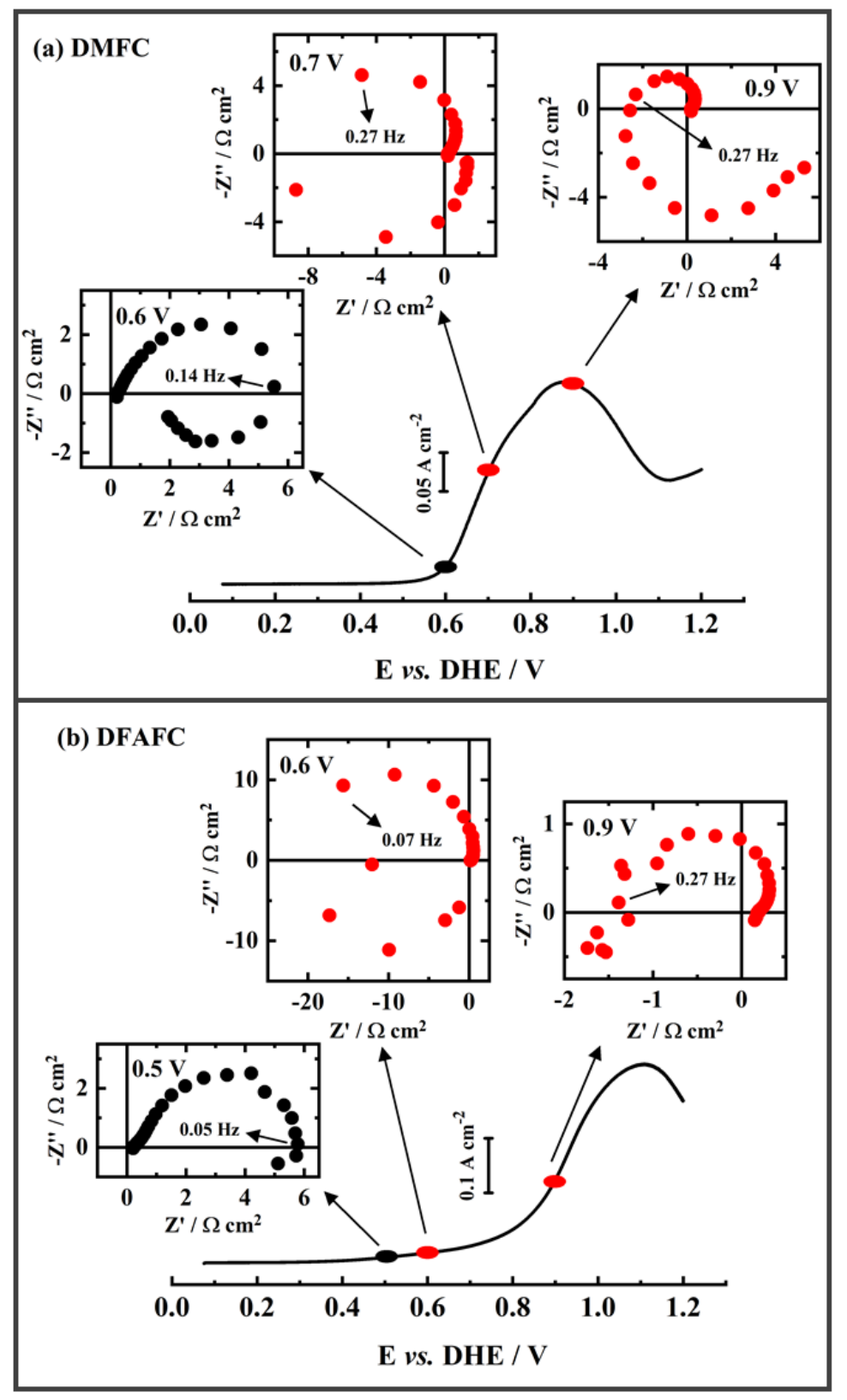

Figure 10. Electrochemical impedance spectra at different potentials for (a) DMFC and (b) DFAFC. The $j-E$ curves for each fuel cell are presented again to locate in which region the spectra were obtained. The Nyquist plots in black indicate a region where oscillatory behavior is not expected, while in red we have the profile of a hidden negative differential resistance (the impedance assumes negative values although the DC curve is still ascending) and transitions from steady-state to oscillatory can occur at these points. $\mathrm{T}=30^{\circ} \mathrm{C} ;\left[\mathrm{CH}_{3} \mathrm{OH}\right]=2 \mathrm{~mol} \mathrm{~L}^{-1} ;[\mathrm{HCOOH}]=8 \mathrm{~mol} \mathrm{~L}^{-1}$.

At $0.90 \mathrm{~V}$ the impedance points for the DMFC follow a clearer trend, with lesser dispersion at low frequencies as in the case of DFAFC. As we increase the potential of both cells, the production of $\mathrm{CO}_{2}$ increases accordingly, and the management of $\mathrm{CO}_{2}$ bubbles becomes a factor in the data acquisition since at the domain of low frequencies diffusion starts to play a greater role. ${ }^{91}$ The $\mathrm{CO}_{2}$ formation at $0.90 \mathrm{~V}$ is much more intense in DFAFC than in 
DMFC, hindering access to steady-state and, therefore, the measurements become noisy as $\omega \rightarrow 0$. This greater production of $\mathrm{CO}_{2}$ in DFAFC occurs because it operated at higher concentrations, but also because $\mathrm{HCOOH}$ electro-oxidation produces only $\mathrm{CO}_{2}$ as a final product, in the case of methanol there are, additionally, formaldehyde and formic acid.

Following in the same direction, Figure 11 shows the EIS experiments for DEFC and DDMEFC, allowing, finally, to compare the four systems. The region where HN-NDR manifests itself during DEFC operation, Figure 11a, is in agreement with the galvanodynamic curves shown in Figure S1c, that is, restricted to a narrow range of potential associated with small current values. In contrast to that observed for DMFC and DFAFC (Figures S1a and S1b) where potential oscillations last for a wider current range. Oscillations during ethanol electro-oxidation, as discussed in Section 3.3, have a more delicate dependence on $\theta_{\mathrm{co}}$, largely because of another strongly adsorbed adsorbate, $\mathrm{CH}_{3} \mathrm{COO}_{\mathrm{ad}}$, which remains on the Pt surface up to $\approx 1 \mathrm{~V} v s$. RHE. $^{77}$ A small increase in potential can favor the pathways that lead to the formation of acetic acid and acetaldehyde, hampering the break of $\mathrm{C}-\mathrm{C}$ bond for the formation of $\mathrm{CO}_{\mathrm{ad}}$. 


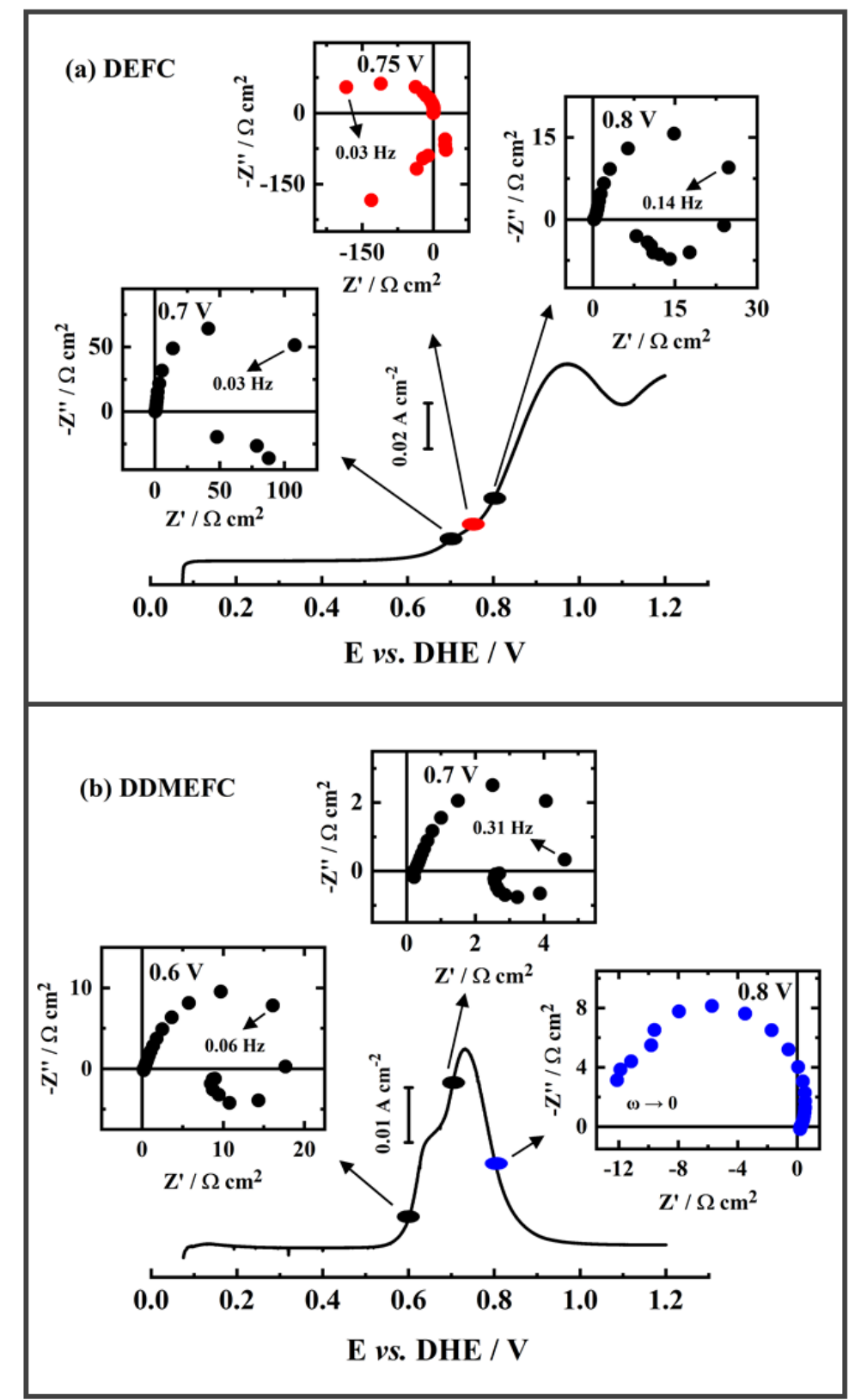

Figure 11. Electrochemical impedance spectra at different potentials for (a) DEFC and (b) DDMEFC. The $j-E$ curves for each fuel cell are presented again to locate in which region the spectra were obtained. The Nyquist plots in black indicate a region where oscillatory behavior is not expected, in red we have the profile of a hidden negative differential resistance (the impedance assumes negative values although in DC conditions $j$ increases as $E$ increases) and in blue a true negative differential resistance (in DC conditions $j$ decreases as $E$ increases). $\mathrm{T}=30^{\circ} \mathrm{C} ;\left[\mathrm{CH}_{3} \mathrm{CH}_{2} \mathrm{OH}\right]=2 \mathrm{~mol} \mathrm{~L}^{-1} ;\left[\mathrm{CH}_{3} \mathrm{OCH}_{3}\right] \approx 1.6 \mathrm{~mol} \mathrm{~L}^{-}$ 1 .

A rather different scenario is observed for DDMEFC. In the region that precedes the peak current during the electro-oxidation of DME (Figure 11b), that is, when $j$ increases as $E$ increases, we did not find a potential value where the impedance spectrum shows hidden negative values of resistance. The NDR profile is only observed when, in fact, the current starts to decrease due to the widespread Pt oxide formation as the potential increases. In this case, the 
weak interaction of DME molecule with the Pt surface affects negatively the rate of all oxidation pathways, even concerning $\mathrm{CO}_{\mathrm{ad}}$ electrode poisoning. Logically, the results presented throughout this paper do not rule out the emergence of oscillatory kinetics during the electrooxidation of DME, studies in higher concentrations as mentioned in Section 3.4 or even tests in potentiostatic mode varying values of external resistance can provide more information about the mechanism associated with the electro-oxidation of DME on Pt. Finally, Table 2 summarizes some of the results discussed throughout this paper.

Table 2. Data obtained for the different fuel cells, where $\omega_{H}$ and $\omega_{g a l v}$ relate, respectively, to the Hopf frequency (EIS) and the average frequency of potential oscillations; $(d E / d t)_{\max }$ is the maximum poisoning rate during an oscillatory cycle; and the apparent activation energies for the system under regular $\left(E_{a p p}\right)$ and oscillatory $\left(E_{\text {app(osc })}\right)$ conditions.

\begin{tabular}{|c|c|c|c|c|c|}
\hline & $\begin{array}{l}\omega_{H^{*}} \\
(\mathbf{H z})\end{array}$ & $\begin{array}{l}\omega_{\text {galv }}{ }^{*} \\
(\mathrm{~Hz})\end{array}$ & $\begin{array}{c}(\mathrm{dE} / \mathrm{dt})_{\max }{ }^{*} \\
\left(\mathrm{~V} \mathbf{s}^{-1}\right)\end{array}$ & $\begin{array}{c}\mathbf{E}_{\mathrm{app}}{ }^{* *} \\
\left(\mathrm{~kJ} \mathrm{~mol}^{-1}\right)\end{array}$ & $\begin{array}{l}\mathbf{E}_{\text {app(osc })^{* * *}} \\
\left(\mathrm{~kJ} \mathrm{~mol}^{-1}\right)\end{array}$ \\
\hline DMFC & 0.4 & $0.44 \pm 0.01$ & 0.25 & $31 \pm 2$ & $46 \pm 2$ \\
\hline DFAFC & 0.15 & $0.008 \pm 0.001$ & 0.91 & $65 \pm 6$ & $113 \pm 7$ \\
\hline DEFC & 0.025 & $0.003 \pm 0.0005$ & 0.04 & $28 \pm 3$ & 0 \\
\hline DDMEFC & --- & --- & --- & $35 \pm 4$ & --- \\
\hline
\end{tabular}

*Data obtained at $30^{\circ} \mathrm{C}$ (Supplementary Information - Figure A2).

**For DMFC, DFAFC and DEFC, the $E_{\text {app }}$ were estimated employing the current density at $0.80 \mathrm{~V}$ during the linear potential scans, except for the DDMEFC where the value at $0.70 \mathrm{~V}$ was used (Supplementary Information - Figure A3).

***Instead of using the current density at a given potential to estimate $E_{a p p}$, for $E_{\text {app(osc) }}$ we used the oscillatory frequency (Supplementary Information - Figure A3).

It is important to highlight that the spontaneous emergence of oscillations along an electrochemical reaction allows us to access information that is inaccessible in conventional voltammetry or steady-state chronopotentio/amperometry. ${ }^{13,30,34,35,37-39,56,57}$ For example, if we evaluate the oscillatory frequency, $\omega_{H}$ or $\omega_{\text {galv }}$, alongside with the maximum poisoning rate during an oscillatory cycle, $(d E / d t)_{\max }$, it is noted that although methanol has a much faster dynamic than ethanol and formic acid, the latter has the highest $d E / d t$ value (Figure $\mathbf{S 2}$ on the Supplementary Information presents $d E / d t$ versus $E$ curves used to estimate $\left.(d E / d t)_{\max }\right)$. This fact reinforces that, from the three molecules, formic acid in an oscillatory regime has the greatest appeal in terms of efficiency gains, ${ }^{13,18,19}$ because during each cycle, the potential remains longer at low potentials, and it is only in a short time interval that reaches its maximum and returns to its minimum (Figure 5). As well highlighted by Delmonde et al., ${ }^{13}$ an electrode 
that has high activity towards organic electro-oxidation might be susceptible to a higher rate of poisoning. The fact that the oscillations in the case of DEFC are confined to a much narrower current/potential range than in DFAFC and DMFC, indicates that the rate of $\mathrm{CO}_{\mathrm{ad}}$, as well as acetic acid and acetaldehyde, formation is slow and the oscillations, during ethanol electrooxidation, are supported due to the interrelation between two adsorbates, $\mathrm{CO}_{\mathrm{ad}}$ and $\mathrm{CH}_{3} \mathrm{COO}_{\text {ad. }}{ }^{39}$ In this same direction, the low activity of the $\mathrm{Pt} / \mathrm{C}$ electrode for dimethyl ether prevents the incidence of oscillatory kinetics.

In terms of the apparent activation energy $\left(E_{a p p}\right)$, there is an $E_{a p p}$ increase in the oscillatory regime for both methanol and formic acid, with the value almost doubling in the latter. By using a mathematical approach called degrees of rate control on an electrokinetic model, Calderón-Cárdenas et al..$^{93}$ observed that a decrease in the activation energy of an elementary step that produces a strongly adsorbed intermediate, blocking active sites, leads to an increase in $E_{a p p}$ since other steps will be inhibited. This may be an indication that the $\mathrm{CO}_{\mathrm{ad}}$ pathway (r13) becomes more prevalent in the oscillatory regime, ${ }^{37}$ since $E_{a p p}$ values around $100 \mathrm{~kJ} \mathrm{~mol}^{-1}$ have been estimated for this reaction on $\mathrm{Pt}^{94}$ However, to distinguish the contributions of each reaction step for the oscillatory frequency and their respective dependencies with the temperature requires the use of in situ and on line techniques to evaluate the coverage of reaction intermediates, with temporal resolution high enough to contemplate the oscillatory period. 


\section{CONCLUSIONS}

We addressed the effect of temperature on direct liquid fuel cells (DLFC) operating with methanol (DMFC), formic acid (DFAFC), ethanol (DEFC), and dimethyl ether (DDMEFC), under regular and oscillatory conditions. The use of identical experimental conditions allowed at studying the role of the fuel on the DLFC performance, providing thus reference values for future investigations. By the polarization curves, an increase in temperature from 30 to $70{ }^{\circ} \mathrm{C}$ leads to a decrease in the overpotential of the electro-oxidation of these molecules (largely due to the formation of Pt oxides at lower potentials) and an increase in current densities. Through galvanodynamic sweeps and electrochemical impedance spectroscopy, we mapped the existence region of potential oscillations on these systems. The DDMEFC did not exhibit oscillatory kinetics. In turn, for DFAFC the oscillatory kinetics lasts up to $70{ }^{\circ} \mathrm{C}$, for DMFC up to $60{ }^{\circ} \mathrm{C}$ and for DEFC up to $50{ }^{\circ} \mathrm{C}$. In addition, the relationship between oscillatory frequency and temperature for DFAFC and DMFC follows an Arrhenius behavior ( $\omega$ increases with $T$ ), while in the case of the DEFC $\omega$ did not present a clear trend with $T$, which appears to be a temperature compensation.

This peculiar behavior of the DEFC was addressed taking into account that during the electro-oxidation of ethanol, another strongly adsorbed intermediate is formed, adsorbed acetate, which reverberates the effect of a low $\mathrm{CO}_{\mathrm{ad}}$ coverage since the break of $\mathrm{C}-\mathrm{C}$ bond on platinum is relatively difficult. This also sheds light on why DME did not show oscillations in the evaluated conditions: the interaction of this molecule with platinum is considered weak compared to the other molecules and leads us to assume that the intricate balance between a poisoning step and one capable of supplying the imposed current density (current carrier), is not achieved in this case. Finally, by EIS it was possible to associate the oscillatory kinetics observed during methanol, formic acid, and ethanol electro-oxidation to a negative differential resistance, more specifically to HN-NDR type oscillators. These dynamics bring to light the peculiarities in the mechanism of each of these reactions that are sometimes masked in a quasistationary response. 


\section{ACKNOWLEDGMENTS}

J.A.N. and H.V. acknowledge São Paulo Research Foundation (FAPESP) for the scholarships (grants \#2015/09295-9 and \#2017/17644-9) and financial support (\#2013/16930-7). H.V. acknowledges Conselho Nacional de Desenvolvimento Científico e Tecnológico (CNPq) for financial support (\#306060/2017-5). This study was financed in part by the Coordenação de Aperfeiçoamento de Pessoal de Nível Superior - Brasil (CAPES) - Finance Code 001. 


\section{REFERENCES}

${ }^{1}$ Kunze, J.; Stimming, U. Electrochemical Versus Heat-Engine Energy Technology: A Tribute to Wilhelm Ostwald's Visionary Statements. Angew. Chem. Int. Ed. 2009, 48, 92309237.

${ }^{2}$ Lamy, C. From hydrogen production by water electrolysis to its utilization in a PEM fuel cell or in a SO fuel cell: Some considerations on the energy efficiencies. Int. J. Hydrog. Energy 2016, 41 (34), 15415-15425.

${ }^{3}$ Gröger, O.; Gasteiger, H. A.; Suchsland, J. Review-Electromobility: Batteries or Fuel Cells? J. Electrochem. Soc. 2015, 162 (14), A2605-A2622.

${ }^{4}$ Nørskov, J. K.; Rossmeisl, J.; Logadottir, A.; Lindqvist, L.; Kitchin, J. R.; Bligaard, T.; Jónsson, H. Origin of the Overpotential for Oxygen Reduction at a Fuel-Cell Cathode. $J$. Phys. Chem. B 2004, 108 (46), 17886-17892.

${ }^{5}$ Shinnar, R. The hydrogen economy, fuel cells, and electric cars. Technol. Soc. 2003, 25 (4), 455-476.

${ }^{6}$ Coutanceau, C.; Baranton, S. Electrochemical conversion of alcohols for hydrogen production: a short overview. WIREs Energy Environ. 2016, 5, 388-400.

${ }^{7}$ Ong, B. C.; Kamarudin, S. K.; Basri, S. Direct liquid fuel cells: A review. Int. J. Hydrog. Energy 2017, 42 (15), 10142-10157.

${ }^{8}$ Corti, H. R., Gonzalez, E. R. Introduction to Direct Alcohol Fuel Cells. In Direct Alcohol Fuel Cells; Corti, H., Gonzalez, E., Eds.; Springer: Dordrecht, 2014; pp 1-32.

${ }^{9}$ Krewer, U.; Vidakovic-Koch, T.; Rihko-Struckmann, L. Electrochemical oxidation of carbon-containing fuels and their dynamics in low-temperature fuel cells. ChemPhysChem 2011, 12, 2518-2544.

${ }^{10}$ Demirci, U. B. Direct liquid-feed fuel cells: Thermodynamic and environmental concerns. J. Power Sources 2007, 169 (2), 239-246.

${ }^{11}$ Kang, Y.; Yang, P.; Markovic, N. M.; Stamenkovic, V. R. Shaping electrocatalysis through tailored nanomaterials. Nano Today 2016, 11 (5), 587-600.

${ }^{12}$ Lee, J.; Eickes, C.; Eiswirth, M.; Ertl, G. Electrochemical oscillations in the methanol oxidation on Pt. Electrochim. Acta 2002, 47 (13-14), 2297-2301.

${ }^{13}$ Delmonde, M. V. F.; Sallum, L. F.; Perini, N.; Gonzalez, E. R.; Schlögl, R.; Varela, H. Electrocatalytic Efficiency of the Oxidation of Small Organic Molecules under Oscillatory Regime. The Journal of Physical Chemistry C 2016, 120, 22365-22374.

${ }^{14}$ Hanke-Rauschenbach, R.; Mangold, M.; Sundmacher, K. Nonlinear dynamics of fuel cells: a review. Rev. Chem. Eng. 2011, 27, 23-52. 
${ }^{15}$ Zhang, J.; Datta, R. Higher Power Output in a PEMFC Operating under Autonomous Oscillatory Conditions in the Presence of CO. Electrochem. Solid-State Lett. 2004, 7 (3), A37-A40.

${ }^{16}$ Lu, H.; Rihko-Struckmann, L.; Hanke-Rauschenbach, R.; Sundmacher, K. Improved electrochemical CO removal via potential oscillations in serially connected PEM fuel cells with PtRu anodes. Electrochim. Acta 2009, 54, 1184-1191.

${ }^{17}$ Mota, A.; Eiswirth, M.; Gonzalez, E. R. Enhanced efficiency of CO-containing hydrogen electroxidation with autonomous oscillations. J. Phys. Chem. C 2013, 117 (24), 12495-12501.

${ }^{18}$ Mota-Lima, A.; Silva, D. R.; Gasparotto, L. H. S.; Gonzalez, E. R. Stationary and damped oscillations in a direct formic acid fuel cell (DFAFC) using Pt/C. Electrochim. Acta 2017, $235,135-142$.

${ }^{19}$ Nogueira, J. A.; Krischer, K.; Varela, H. Coupled Dynamics of Anode and Cathode in Proton Exchange Membrane Fuel Cells. ChemPhysChem 2019, 20, 3081-3088.

${ }^{20}$ Schultz, T.; Krewer, U.; Sundmacher, K. Impact of electrode kinetics on the dynamic response of a DMFC to change of methanol feed concentration. J. Power Sources 2007, 165 (1), 138-151.

${ }^{21}$ Krewer, U.; Kamat, A.; Sundmacher, K. Understanding the dynamic behaviour of direct methanol fuel cells: Response to step changes in cell current. J. Electroanal. Chem. 2007, 609 (2), 105-119.

${ }^{22}$ Joghee, P.; Pylypenko, S.; Wood, K.; Corpuz, A.; Bender, G.; Dinh, H. N.; O'Hayre, R. Improvement in direct methanol fuel cell performance by treating the anode at high anodic potential. J. Power Sources 2014, 245, 37-47.

${ }^{23}$ Majidi, P.; Pickup, P. G. Improving carbon dioxide yields and cell efficiencies for ethanol oxidation by potential scanning. J. Power Sources 2014, 269, 173-179.

${ }^{24}$ Martín-Yerga, D.; Yu, X.; Terekhina, I.; Henriksson, G.; Cornell, A. In situ catalyst reactivation for enhancing alcohol electro-oxidation and coupled hydrogen generation. Chem. Commun. 2020, 56, 4011-4014.

${ }^{25}$ Richter, P. H.; Rehmus, P.; Ross, J. Control and Dissipation in Oscillatory Chemical Engines. Prog. Theor. Phys. 1981, 66 (2), 385-405.

${ }^{26}$ Lazar, J. G.; Ross, J. Changes in mean concentration, phase shifts, and dissipation in a forced oscillatory reaction. Science 1990, 247 (4939), 189-192.

${ }^{27}$ Lee, J.; Christoph, J.; Strasser, P.; Eiswirth, M; Ertl, G. Existence regions of spatiotemporal patterns in the electro-oxidation of formic acid. Phys. Chem. Chem. Phys. 2003, 5, 935-938.

${ }^{28}$ Christoph, J.; Noh, T.; Lee, J.; Strasser, P.; Eiswirth, M. Spatiotemporal self-organization in the oscillatory $\mathrm{HCOOH}$ oxidation on a Pt ribbon electrode - Theory and experiments. Surf.

Sci. 2009, 603 (10-12), 1652-1661. 
${ }^{29}$ Kiss, I. Z.; Munjal, N.; Martin, R. S. Synchronized current oscillations of formic acid electro-oxidation in a microchip-based dual-electrode flow cell. Electrochim. Acta 2009, 55 (2), 395-403.

${ }^{30}$ Nagao, R.; Epstein, I. R.; Gonzalez, E. R; Varela, H. Temperature (Over)Compensation in an Oscillatory Surface Reaction. J. Phys. Chem. A 2008, 112, 4617-4624.

${ }^{31}$ Nagao, R.; Sitta, E.; Varela, H. Stabilizing Nonstationary Electrochemical Time Series. J. Phys. Chem. C 2010, 114 (50), 22262-22268.

${ }^{32}$ Zülke, A. A.; Varela, H. The effect of temperature on the coupled slow and fast dynamics of an electrochemical oscillator. Sci. Rep. 2016, 6, 24553.

${ }^{33}$ Sallum, L. F.; Mota-Lima, A.; Gonzalez, E. R. Galvano- and Potentio-dynamic studies during ethanol electro-oxidation reaction in acid vs. alkaline media: Energy dissipation and blocking nature of potassium. Electrochim. Acta 2019, 293, 247-259.

${ }^{34}$ Calderón-Cárdenas, A.; Hartl, F. W.; Gallas, J. A. C; Varela, H. Modeling the triple-path electro-oxidation of formic acid on platinum: Cyclic voltammetry and oscillations. Catal. Today, 2019. In press.

${ }^{35}$ Boscheto, E.; Batista, B. C.; Lima, R. B.; Varela, H. A surface-enhanced infrared absorption spectroscopic (SEIRAS) study of the oscillatory electro-oxidation of methanol on platinum. J. Electroanal. Chem. 2010, 642 (1), 17-21.

${ }^{36}$ Carbonio, E. A.; Nagao, R. Gonzalez E. R.; Varela, H. Temperature effects on the oscillatory electro-oxidation of methanol on platinum. Phys. Chem. Chem. Phys. 2009, 11, 665-670.

${ }^{37}$ HARTL, F. W.; ZÜLKE, A. A.; FONTE, B. J.; Varela, H. Temperature dependence of the evolving oscillations along the electrocatalytic oxidation of methanol. J. Electroanal. Chem. 2017, 800, 99-105.

${ }^{38}$ Sallum, L. F.; Gonzalez, E. R.; Mota-Lima, A. Quantifying the turnover frequency for ethanol electro-oxidation on polycrystalline $\mathrm{Pt}$ in acid and alkaline media. Electrochem. commun. 2018, 90, 26-29.

${ }^{39}$ Silva, M. F.; Delmonde, M. V. F.; Batista, B. C.; Boscheto, E.; Varela, H.; Camara, G. A. Oscillatory electro-oxidation of ethanol on platinum studied by in situ ATR-SEIRAS.

Electrochim. Acta 2019, 293, 166-173.

${ }^{40}$ Nogueira, J. A.; Arias, I. K. P.; Vidakovic-Koch, T.; Varela, H.; Sundmacher, K. Autonomous Voltage Oscillations in a Direct Methanol Fuel Cell. Electrochim. Acta 2016, $212,545-552$.

${ }^{41}$ Nogueira, J. A.; Varela, H. Voltage Inversion Caused by Self-organized Oscillations in a Direct Formic Acid Fuel Cell. Matters 2017. (DOI: 10.19185/matters.201705000005).

${ }^{42}$ Mota, A.; Gonzalez, E. R. Enhanced efficiency with autonomous oscillations: challenges for DAFC. ECS Transactions 2013, 58 (1), 1879-1884. 
${ }^{43}$ Zhang, J.; Datta, R. Sustained Potential Oscillations in Proton Exchange Membrane Fuel Cells with PtRu as Anode Catalyst. J. Electrochem. Soc. 2002, 149 (11), A1423-A1431.

${ }^{44}$ Paganin, V. A.; Ticianelli, E. A.; Gonzalez, E. R. Development and electrochemical studies of gas diffusion electrodes for polymer electrolyte fuel cells. J. Appl. Electrochem. 1996, 26 (3), 297-304.

${ }^{45}$ Müller, J. T.; Urban, P. M.; Hölderich, W. F.; Colbow, K. M.; Zhang, J.; Wilkinson, D. P. Electro-oxidation of Dimethyl Ether in a Polymer-Electrolyte-Membrane Fuel Cell. $J$. Electrochem. Soc. 2000, 147 (11), 4058-4060.

${ }^{46}$ Küver, A.; Vogel, I.; Vielstich, W. Distinct performance evaluation of a direct methanol SPE fuel cell. A new method using a dynamic hydrogen reference electrode. J. Power Sources 1994, 52 (1), 77-80.

${ }^{47}$ Schmidt, T. J.; Stamenkovic, V.; Ross Jr., P. N.; Markovic, N. M. Temperature dependent surface electrochemistry on Pt single crystals in alkaline electrolyte. Part 3. The oxygen reduction reaction. Phys. Chem. Chem. Phys. 2003, 5, 400-406.

${ }^{48}$ Gurau, B.; Smotkin, E. S. Methanol crossover in direct methanol fuel cells: a link between power and energy density. J. Power Sources 2002, 112 (2), 339-352.

${ }^{49}$ Song, S. Q.; Zhou, W. J.; Li, W. Z.; Sun, G.; Xin, Q.; Kontou, S.; Tsiakaras, P. Direct Methanol Fuel Cells: Methanol Crossover and its Influence on Single DMFC Performance. Ionics 2004, 10, 458-462.

${ }^{50}$ Iwasita, T. Electrocatalysis of methanol oxidation. Electrochim. Acta 2002, 47 (22-23), 3663-3674.

${ }^{51}$ Housmans, T. H. M.; Wonders, A. H.; Koper, M. T. M. Structure Sensitivity of Methanol Electrooxidation Pathways on Platinum: an on-line Electrochemical Mass Spectrometry Study. J. Phys. Chem. B 2006, 110 (20), 10021-10031.

${ }^{52}$ Cohen, J. L.; Volpe, D. J.; Abruña, H. D. Electrochemical determination of activation energies for methanol oxidation on polycrystalline platinum in acidic and alkaline electrolytes. Phys. Chem. Chem. Phys. 2007, 9, 49-77.

${ }^{53}$ Chen, Y. X.; Miki, A.; Ye, S.; Sakai, H.; Osawa, M. Formate, an Active Intermediate for Direct Oxidation of Methanol on Pt Electrode. J. Am. Chem. Soc. 2003, 125, 3680-3681.

${ }^{54}$ Gilroy, D.; Conway, B. E. Surface oxidation and reduction of platinum electrodes: Coverage, kinetic and hysteresis studies. Can. J. Chem. 1968, 46 (6), 875-890.

${ }^{55}$ Imbihl, R.; Ertl, G. Oscillatory Kinetics in Heterogeneous Catalysis. Chem. Rev. 1995, 95 (3), 697-733.

${ }^{56}$ Silva, K. N.; Sitta, E. Tuning oscillatory time-series evolution by $\mathrm{Pt}(111)-\mathrm{OH}_{\mathrm{ad}}$ stabilization. J. Solid State Electrochem. 2020, 24, 1921-1926. 
${ }^{57}$ Sitta, E.; Nascimento, M. A.; Varela, H. Complex kinetics, high frequency oscillations and temperature compensation in the electro-oxidation of ethylene glycol on platinum. Phys. Chem. Chem. Phys. 2010, 12, 15195-15206.

${ }^{58}$ Chojak-Halseid, M.; Jusys, Z.; Behm, R. J. Methanol oxidation over a Pt/C catalyst at high temperatures and pressure: an online electrochemical mass spectrometry study. J. Phys. Chem. C 2010, 114, 22573-22581.

${ }^{59}$ Koper, M. T. M. Non-linear phenomena in electrochemical systems. J. Chem. Soc. Faraday Trans. 1998, 94, 1369-1378.

${ }^{60}$ Strasser, P.; Eiswirth, M.; Koper, M. T. M. Mechanistic classification of electrochemical oscillators - an operational experimental strategy. J. Electroanal. Chem. 1999, 478, 50-66.

${ }^{61}$ Joo, J.; Uchida, T.; Cuesta, A.; Koper, M. T. M.; Osawa, M. Importance of acid-base equilibrium in electrocatalytic oxidation of formic acid on platinum. J. Am. Chem. Soc. 2013, 135 (27), 9991-9994.

${ }^{62}$ Chen, Y. X.; Heinen, M.; Jusys, Z.; Behm, R. J. Bridge-Bonded Formate: Active Intermediate or Spectator Species in Formic Acid Oxidation on a Pt Film Electrode? Langmuir 2006, 22, 10399-10408.

${ }^{63}$ Perales-Rondón, J. V.; Herrero, E.; Feliu, J. M. On the activation energy of the formic acid oxidation reaction on platinum electrodes. J. Electroanal. Chem. 2015, 742, 90-96.

${ }^{64}$ Paganin, V. A.; Sitta, E.; Iwasita, T.; Vielstich, W. Methanol crossover effect on the cathode potential of a direct PEM fuel cell. J. Appl. Electrochem. 2005, 35, 1239-1243.

${ }^{65}$ Jeong, K. J.; Miesse, C. M.; Choi, J. H.; Lee, J.; Han, J.; Yoon, S. P.; Nam, S. W.; Lim, T. H.; Lee, T. G. Fuel crossover in direct formic acid fuel cells. J. Power Sources 2007, 168 (1), 119-125.

${ }^{66}$ Song, S.; Zhou, W.; Liang, Z.; Cai, R.; Sun, G.; Xin, Q.; Stergiopoulos, V.; Tsiakaras, P. The effect of methanol and ethanol cross-over on the performance of PtRu/C-based anode DAFCs. Appl. Catal. B 2005, 55 (1), 65-72.

${ }^{67}$ Zhu, Y.; Ha, S. Y.; Masel, R. I. High power density direct formic acid fuel cells. J. Power Sources 2004, 130, 8-14.

${ }^{68}$ Tripkovic, D. V.; Popovic, K. Dj.; Jovanovic, V. M.; Nogueira, J. A.; Varela, H.; Lopes, P. P.; Strmcnik, D.; Stamenkovic, V. R.; Markovic, N. M. Tuning of catalytic properties for electrooxidation of small organic molecules on Pt-based thin films via controlled thermal treatment. J. Catal. 2019, 371, 96-105.

${ }^{69}$ Eiswirth, M.; Bürger, J.; Strasser, P.; Ertl, G. Oscillating Langmuir-Hinshelwood Mechanisms. J. Phys. Chem. 1996, 100, 19118-19123.

${ }^{70}$ Pell, W. G.; Zolfaghari, A.; Conway, B. E. Capacitance of the double-layer at polycrystalline Pt electrodes bearing a surface-oxide film. J. Electroanal. Chem. 2002, 532, $13-23$. 
${ }^{71}$ Sampaio, M. R.; Rosa, L. P.; D'Agosto, M. A. Ethanol-electric propulsion as a sustainable technological alternative for urban buses in Brazil. Renew. Sust. Energ. Rev. 2007, 11 (7), 1514-1529.

${ }^{72}$ Akhairi, M. A. F.; Kamarudin, S. K. Catalysts in direct ethanol fuel cell (DEFC): an overview. Int. J. Hydrog. Energy 2016, 41, 4214-4228.

${ }^{73}$ Wang, H.; Jusys, Z.; Behm, R. J. Ethanol electro-oxidation on carbon-supported Pt, PtRu and $\mathrm{Pt}_{3}$ Sn catalysts: A quantitative DEMS study. J. Power Sources 2006, 154, 351-359.

${ }^{74}$ Cantane, D. A.; Ambrosio, W. F.; Chatenet, M.; Lima, F.H.B. Electro-oxidation of ethanol on $\mathrm{Pt} / \mathrm{C}, \mathrm{Rh} / \mathrm{C}$, and $\mathrm{Pt} / \mathrm{Rh} / \mathrm{C}$-based electrocatalysts investigated by on-line DEMS. $J$.

Electroanal. Chem. 2012, 681, 56-65.

${ }^{75}$ Braunchweig, B.; Hibbitts, D.; Neurock, M.; Wieckowski, A. Electrocatalysis: A direct alcohol fuel cell and Surf. Sci. perspective. Catal. Today 2013, 202, 197-209.

${ }^{76}$ Martins, C. A.; Fernández, P. S.; Troiani, H. E.; Martins, M. E.; Camara, G. A. Ethanol vs. glycerol: Understanding the lack of correlation between the oxidation currents and the production of $\mathrm{CO}_{2}$ on Pt nanoparticles. J. Electroanal. Chem. 2014, 717-718, 231-236.

${ }^{77}$ Heinen, M.; Jusys, Z.; Behm, R. J. Ethanol, Acetaldehyde and Acetic Acid Adsorption/Electrooxidation on a Pt Thin Film Electrode under Continuous Electrolyte Flow: an in situ ATR-FTIRS Flow Cell Study. J. Phys. Chem. C 2010, 114 (21), 9850-9864.

${ }^{78}$ Sun, S.; Halseid, M. C.; Heinen, M.; Jusys, Z.; Behm, R. J. Ethanol electrooxidation on a carbon-supported Pt catalyst at elevated temperature and pressure: A high-temperature/highpressure DEMS study. J. Power Sources 2009, 190 (1), 2-13.

${ }^{79}$ Nonaka, H.; Matsumura, Y. Electrochemical oxidation of carbon monoxide, methanol, formic acid, ethanol, and acetic acid on a platinum electrode under hot aqueous conditions. $J$. Electroanal. Chem., 520 (1-2), 101-110.

${ }^{80}$ Chen, S.; Schell, M. Bistability and excitability in the electrochemical oxidation of ethanol. Electrochim. Acta 1999, 44, 4773-4780.

${ }^{81}$ Lamy, C.; Jaubert, T.; Baranton, S.; Coutanceau, C. Clean hydrogen generation through the electrocatalytic oxidation of ethanol in a Proton Exchange Membrane Electrolysis Cell (PEMEC): Effect of the nature and structure of the catalytic anode. J. Power Sources 2014, 245, 927-936.

${ }^{82}$ Mench, M. M.; Chance, H. M.; Wang, C. Y. Direct Dimethyl Ether Polymer Electrolyte Fuel Cells for Portable Applications. J. Electrochem. Soc. 2004, 151 (1), A144-A150.

${ }^{83}$ Semelsberger, T. A.; Borup, R. L.; Greene, H. L. Dimethyl ether (DME) as an alternative fuel. J. Power Sources 2006, 156 (2), 497-511.

${ }^{84}$ Kerangueven, G.; Coutanceau, C.; Sibert, E.; Léger, J.-M.; Lamy, C. Methoxy methane (dimethyl ether) as an alternative fuel for direct fuel cells. J. Power Sources 2006, 157 (1), 318-324. 
${ }^{85} \mathrm{Yu}$, J.; Choi, H.; Cho, S. M. Performance of direct dimethyl ether fuel cells at low temperature. Electrochem. commun. 2005, 7 (12), 1385-1388.

${ }^{86}$ Kerangueven, G.; Coutanceau, C.; Sibert, E.; Hahn, F.; Léger, J- M.; Lamy, C. Mechanism of di(methyl)ether (DME) electrooxidation at platinum electrodes in acid medium. J. Appl. Electrochem. 2006, 36, 441-448.

${ }^{87}$ Liu, Y.; Muraoka, M.; Mitsushima, S.; Ota, K.; Kamiya, N. Electrochemical and ATRFTIR study of dimethyl ether and methanol electro-oxidation on sputtered Pt electrode. Electrochim. Acta 2007, 52 (19), 5781-5788.

${ }^{88}$ Zhang, Y.; Lu, L.; Tong, Y.; Osawa, M.; Ye, S. Electrochemical and infrared study of electro-oxidation of dimethyl ether (DME) on platinum polycrystalline electrode in acid solutions. Electrochim. Acta 2008, 53 (21), 6093-6103.

${ }^{89}$ Li, H.; Calle-Vallejo, F.; Kolb, M. J.; Kwon, Y.; Li, Y.; Koper, M. T. M. Why ( 1000$)$ Terraces Break and Make Bonds: Oxidation of Dimethyl Ether on Platinum Single-Crystal Electrodes. J. Am. Chem. Soc. 2013, 135 (38), 14329-14338.

${ }^{90}$ Lu, L.; Yin, G.; Tong, Y.; Zhang, Y.; Gao, Y.; Osawa, M.; Ye, S. Electrochemical behaviors of dimethyl ether on platinum single crystal electrodes. Part I: $\operatorname{Pt}(111) . J$. Electroanal. Chem. 2008, 619-620, 143-151.

${ }^{91}$ Koper, M. T. M. Oscillations and complex dynamical bifurcations in electrochemical systems. In Advances in Chemical Physics; Prigogine, I.; Rice, S. A., Eds.; John Wiley \& Sons: New York, 1996. Vol. 92, pp 161-298.

${ }^{92}$ Orlik, M. Application of Impedance Spectroscopy to Electrochemical Instabilities. In Self-Organization in Electrochemical Systems I. General Principles of Self-organization. Temporal Instabilities; Scholz, F., Eds.; Monographs in Electrochemistry; SpringerVerlag: Berlin Heidelberg, 2012. Vol. 1, pp 111-195.

${ }^{93}$ Calderón-Cárdenas, A.; Paredes-Salazar, E. A.; Varela, H. Apparent Activation Energy in Electrochemical Multistep Reactions: a Description via Sensitivities and Degrees of Rate Control. ACS Cat. 2020, in press. doi.org/10.1021/acscatal.0c02359.

${ }^{94}$ Geng, B.; Cai, J.; Liang, S.; Liu, S. X.; Li, M. F.; Chen, Y.-X. Temperature effects on CO adsorption/desorption at Pt film electrodes: an electrochemical in situ infrared spectroscopic study. Phys. Chem. Chem. Phys. 2010, 12, 10888-10895. 